\title{
Evolving long-distance passenger services. Market concentration, fares and specialisation patterns in Italy
}

\author{
Paolo BERIA* ${ }^{* 1}$, Alberto BERTOLIN ${ }^{1}$ \\ ${ }^{1}$ Politecnico di Milano, Italy \\ * corresponding author: Beria Paolo, via Bonardi 3, 20133 Milano, Italy. paolo.beria@polimi.it
}

\begin{abstract}
Despite its importance, the analysis of long-distance transport dynamics and policies has not reached the same understanding of local transport services. One reason is the market-driven nature with respect to the planningdriven one, which makes the most important planning decisions taken internally to the firms.

The aim of this paper is to discuss quantitatively the main characteristics of long-distance transport in a liberalised environment (Italy) in terms of market concentration levels, fares and product specialisation. We will consider rail, coach and carpooling services, which are not fully separate markets and interact in terms of supply, prices and groups of customers.

The paper also discusses one of the main remaining regulatory issue, in Italy but also in other deregulated markets, which is the potential distortions due to the overlap of subsidised and planned Public Service Obligations with market services.
\end{abstract}

\section{Keywords}

Long-distance transport; passenger transport; fares; rail; coach; specialisation; Italy.

\section{Acknowledgements}

The research is part of the project "QUAINT" (protocol: RBSI14JR1Z), supported by the Italian Ministry of Education University and Research (MIUR), within the SIR programme (D.D. n. 197 del 23 gennaio 2014). 


\section{Introduction and aims}

Long-distance transport has been central since the beginning in the European agenda (EC, 1992), both focusing on infrastructural dimension (trans-European networks programme) and especially on markets liberalisation. Nearly thirty years later, it resulted clear that the expected effects of infrastructural plans were just partially met (EC, 2009), especially in terms of international connectivity. The results of the liberalisation processes and creation of a level-playing field, instead, are much more visible to the citizens, even if at different pace depending on the transport mode. However, to obtain a smooth functioning of and effective competition in the internal market, there is further work to do to eliminate all residual barriers between modes and national systems, easing the process of integration and facilitating the emergence of multinational and multimodal operators (EC, 2011).

Despite its importance, the analysis of long-distance transport markets and structure has not reached the same level of deepening of the local transport services. One reason is that the market-driven component is historically, and especially now that liberalisation goes on, dominant with respect to the planning-driven one. Consequently, data is more scant and documents, such as plans, simply does not exist being the most important planning decisions taken internally to the firms.

Actually, there is not a straight definition of what "long-distance" is, sometimes even within one country. In some countries, for example Germany, the boundary between short- and long-distance is based on a distance threshold (e.g. $100 \mathrm{~km}$ ). This definition is very simple but, at the same time, it might introduce biases: commuting could exist beyond the threshold and tourism (leisure or business) could remain below. In other cases, the definition is normative. For example, in Italy, transport between one or two regions is planned and ruled by regions and therefore is not considered "long-distance". In the following we will refer to a general definition, which is coherent with the definition used in the country-case, and is based on the market structure (which in turn depends on the legal framework). We consider "long-distance" everything that is not ruled by a local-scale regulation, normally a PSO. Consequently, a national-scale PSO is "long-distance", as well as regional connections operated under market conditions (e.g. parts of longer intercity coach lines).

This paper tries to contribute to the understanding of long-distance transport markets, analysing Italian situation by means of a large dataset including multimodal supply, geography and fares. ${ }^{1}$ To date, Italy is an interesting case to base the discussion, as it is probably one of the European countries where liberalisation in long-distance markets is more advanced ${ }^{2}$ and more pervasive. Inside the national borders a large newcomer competes with the incumbent for the densest rail routes, many coach companies (both incumbents and newcomers) are battling for the recently opened coach market, and Alitalia's leadership has faded away long time ago, leaving a highly competitive air sector.

More precisely, in the core of the paper we will:

a. Measure the levels of intramodal and intermodal competition. This will let us clarify the borders between contestable and incontestable markets, and between market and public service obligations (PSO);

b. Compute the fare levels of rail and coach sectors. This will let us introduce if, and how much, direct competition affects prices, but also clarify the different fare structures;

c. Show how long-distance products specialised, in terms of both services differentiation and nichefocus.

The paper follows with an overview of European policies in the long-distance sector (Section 2), and with a concise introduction to Italian case study (Section 3). The Sections 4, 5 and 6 correspond with the three above-

\footnotetext{
${ }^{1}$ The empirical data we will refer to have been collected during the project QUAINT, aimed at describing the entire longdistance transport sector in Italy and at creating a multimodal transport model. More details on the project can be found in Beria et al. (2017b).

${ }^{2}$ Differently from local public transport where Italy is not a best practice, being most of cities and regions still using inhouse or direct contract provision.
} 
mentioned elaborations on competition level, fares and specialization. Section 7 moves forward discussing the effect of the overlapping of PSO and market services and Section 8 concludes. In Annex, a note on the calculation of fares is provided.

\section{Overview of European long-distance policies in market opening}

We have already commented on the two-sided European policy in the long-distance: infrastructure and liberalisation. The European policy in the infrastructure side consisted in the creation of international "corridors" where traffic, and in particular international one, was concentrated and made easier. Practically, many international lines or upgrades have been funded, as well as highway segments and airports. However, the domestic dimension of long-distance transport remains prevalent (especially in larger countries) and, in this sense, the European infrastructural vision has not been fully deployed (ECA, 2018).

On the market side, the principle followed was that of liberalisation through removal of any market barrier to a unique domestic market. This is extremely more visible in the air sector, where today "domestic" means European rather than national. The recent but quick liberalisation of coach sector, where entry barriers were normative and never economic or physical, goes in the same direction, with a consolidation of the sector across a handful of European operators. Due to its intrinsic characteristics (vertical integration, national operators, etc.), but also to the vested interests (national industry protection, unions, etc.), rail sector has moved at a much slower pace.

The result of these actions, especially the second one, has driven to a situation not yet homogeneous in the continent, but generally coherent. In many cases, the largest differences lay in the different speed of implementation of policies rather than in radically different regulatory frameworks. The following paragraphs outline the general characteristics of the three relevant modal sub-markets resulting from liberalisation, with particular reference to the Italian case. For a more critical overview, refer to Ponti et al. (2013).

\subsection{Air transport}

European action deployed in three "liberalisation packages" between 1987 and 1993. Their aim was to liberalise completely the continental market in terms of "open sky". Today the European market is, de facto, a domestic market. Airlines compete in the market, without any prescription in terms of fares, network, timetables, ownership, etc. Exceptions are allowed to guarantee a minimum level of accessibility for remote regions through PSO contracts. In addition, start-up contributions are allowed to support the launch of new routes. Intercontinental routes are ruled by bilateral agreements except for those areas where Europe has contracted specific "open sky” agreements, such as for the North Atlantic.

While airlines are almost fully liberalised, airports instead require regulation. One issue, in some cases acting as a significant entry barrier, is that of slot allocation. The rule adopted in Europe is that of "grandfathered rights”, i.e. slots are not traded but are maintained by a company as long as it uses it continuously.

Italian case does not present any specific regulatory situation, being adherent to European norms. The main element of distinction for Italy is the long-lasting weakness of the (former) flag-carrier Alitalia. This weakness, passed through numerous crises, privatisations and restructuring plans (Beria et al., 2011 and 2013) has made the Italian market much more "porous" to newcomers than countries with a strong national player. Nowadays Italy is among the countries with the highest share of low-cost carriers and typically the second continental market of many key players (e.g. Ryanair, easyJet and Volotea).

\subsection{Railways}

The liberalisation process of European rail industry, despite following similar principles, has been much longer. Except for the UK, continental Europe focused on vertical unbundling of the entire network, without privatisation. The separation, societal or at least in form of holding, of infrastructure and services was seen as the pre-requisite for competition, being it for the market (in the regional transport) or in the market (as first 
option for the long-distance). The third rail liberalisation package of 2007 liberalised, since 2010, international rail cabotage, allowing any European rail company to operate any international service including domestic relations.

Actually, in the long-distance, cases of liberalisation that left the pages of the laws and reached the reality of the market are very scant. Again, except UK, tenders for long-distance PSOs are rare (used for example in Sweden; Alexandersson \& Hultén, 2008). International open-access is used limitedly and only by incumbent companies or companies which usually are consortia of national incumbents. ${ }^{3}$ The most interesting things have happened in a limited group of countries, which liberalised the domestic segment before the European deadlines. Italy, Czech Republic, Sweden, Slovakia and Austria (Beria \& Grimaldi, 2017) are the countries where open-access competition is a reality of some quantitative importance. In Germany, among the first movers, open access exists but operating in micro-niches. Interestingly, in all of these cases, the newcomer is not a foreign incumbent, but a private company, often just founded. ${ }^{4}$

\subsection{Coach}

Coach transport has historically been marginal in most of European countries, dominated by rail. Coach held important market shares in some eastern countries (e.g. Poland) or in countries with ineffective railways because of scarce traffic (e.g. Ireland) or because of long distances and orography (e.g. Norway). Looking better, coach was already an alternative under specific conditions, for example in North-South Italian immigration routes or in the connections between Berlin and the rest of Western Germany before unification.

Early cases of domestic coach liberalisation are in UK (White \& Robbins, 2012), Sweden and Norway (Alexandersson et al., 2010; Aarhaug \& Fearnley, 2016). They show that after a period of steep growth, also in markets that were originally captive of rail or plane, evolution slowed down when maturity was reached. The most impressive cases of coach liberalisation has happened recently and evolved extremely quickly. German, Italian and French (Augustin et al., 2014; Dürr et al., 2016; Dürr \& Hüschelrath, 2017; Blayac \& Bougette, 2017; Grimaldi et al., 2017) coach sector passed in a few years from an unknown niche to the headlines of newspapers, partially reproducing what has happened ten years ago with the low-cost airlines.

\section{A glimpse of Italian long-distance transport networks}

In a country like Italy, made of many large and continuous areas of high population density (coastlines, Po Valley,...), any definition of long-distance would be difficult and imprecise. However, from the normative point of view such classification exists, and generates some distortions. In rail transport, Regions manage regional and interregional traffic and "long-distance" is everything else, partially under Ministry's planning and operated under PSO, and mainly left to the market. However, this classification entails no distance threshold and the differences between Regions' sizes may create incoherent situations (e.g. Mantua - Milan is a $160 \mathrm{~km}$ regional service, while Turin - Milan, run on the same distance, is interregional). Same for coaches: law specifies that everything connecting “3 or more regions” is “long-distance”. Therefore, a 200 km Pescara - Rome coach is "long-distance", while Bari - Naples $(270 \mathrm{~km})$ is "interregional”. These examples makes no sense from the functional point of view, but the distinction is clear and works for most of the cases.

\subsection{Rail supply}

Rail supply is quite adherent to Italian urban structure. Figure 1 depicts all Italian trains in terms of trains/day. Apart the concentration around main cities, which are local trains, the main corridors connect Milan and Venice to Naples (the HS network) and Turin to Venice. Other important lines are the Brenner line, the northern part

\footnotetext{
${ }^{3}$ For example, Thalys is $62 \%$ SNCF, $28 \%$ SNCB and $10 \%$ DB. Eurostar is a consortium formed by SNCB, SNCF, National Express Group and British Airways.

${ }^{4}$ Actually, the Swedish open-access operator MTR is the Hong Kong public transport incumbent.
} 
of the Tyrrhenian coast and the Adriatic line. South of Naples lines becomes thin, regional trains almost disappear (excluding Apulia) and the service is left to frequently stopping long-distance Intercity trains. 


\section{Train services flows}

Our elaborations on 2016 Train company timetables - average day

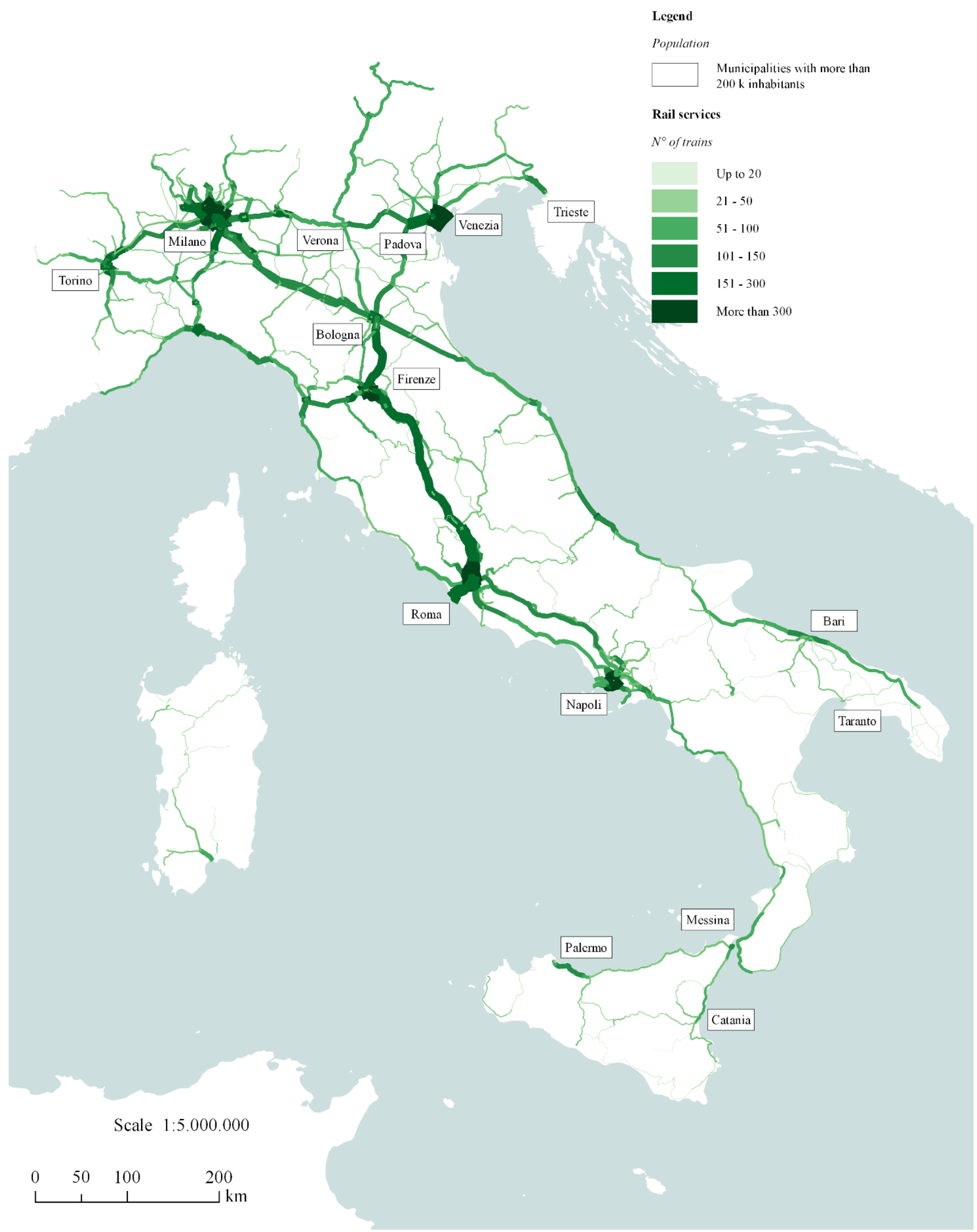

Figure 1. Long-distance trains: number of daily services, year 2016. Source: our elaborations on 2016 Rail Timetable-average winter weekday. 
As already mentioned, Italy is home of one of the largest private long-distance rail operator, NTV, which operates under the commercial name of "Italo" 5 and compete with the national incumbent, Trenitalia, present in all market, PSO and regional segments (Figure 2).

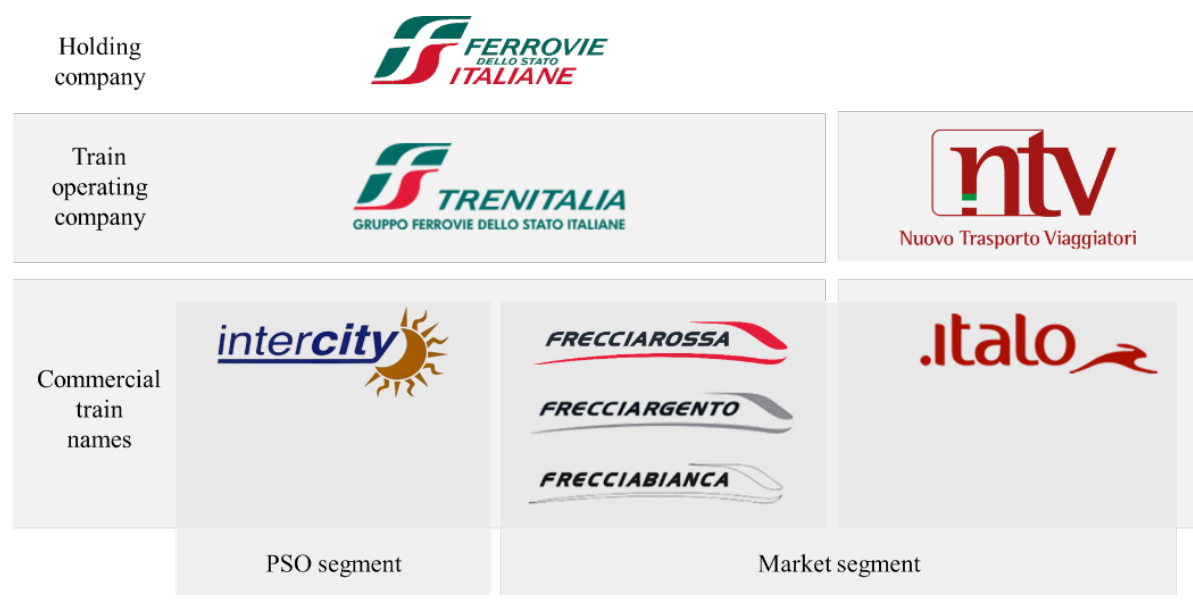

Figure 2. Rail companies and brands present in the Italian long-distance domestic market

\subsection{Coach}

Large or small, rail transport represents the most common option for long-distance transport mode among cities. However, and this is quite a specificity of Italy among the larger European countries, another mode is historically serving sparse and depopulated areas: coach. Figure 3 depicts the historical coach network, before the liberalisation (Grimaldi et al., 2017). It is well evident the penetration of coaches in the deepest and sparsest territories of Apulia, Calabria, Basilicata and Sicily. There, almost every village has a handful of direct rides per week to Rome, Naples and most likely also to Milan and the north. This structure has only partially been changed by the "revolution" occurred since 2012, with the entry of large international operators (Megabus first and then Flixbus, followed by the expansion of some Italian companies).

\footnotetext{
${ }^{5}$ In the rest of the paper we will use NTV when referring to the company (for example when comparing with Trenitalia). We will instead use "Italo" when referring to the product, which in the case of Trenitalia has different names (IC, Frecciarossa, etc.).
} 


\section{Coach services flows}

Our elaborations on 2015/16 Coach company timetables - Winter average weekday

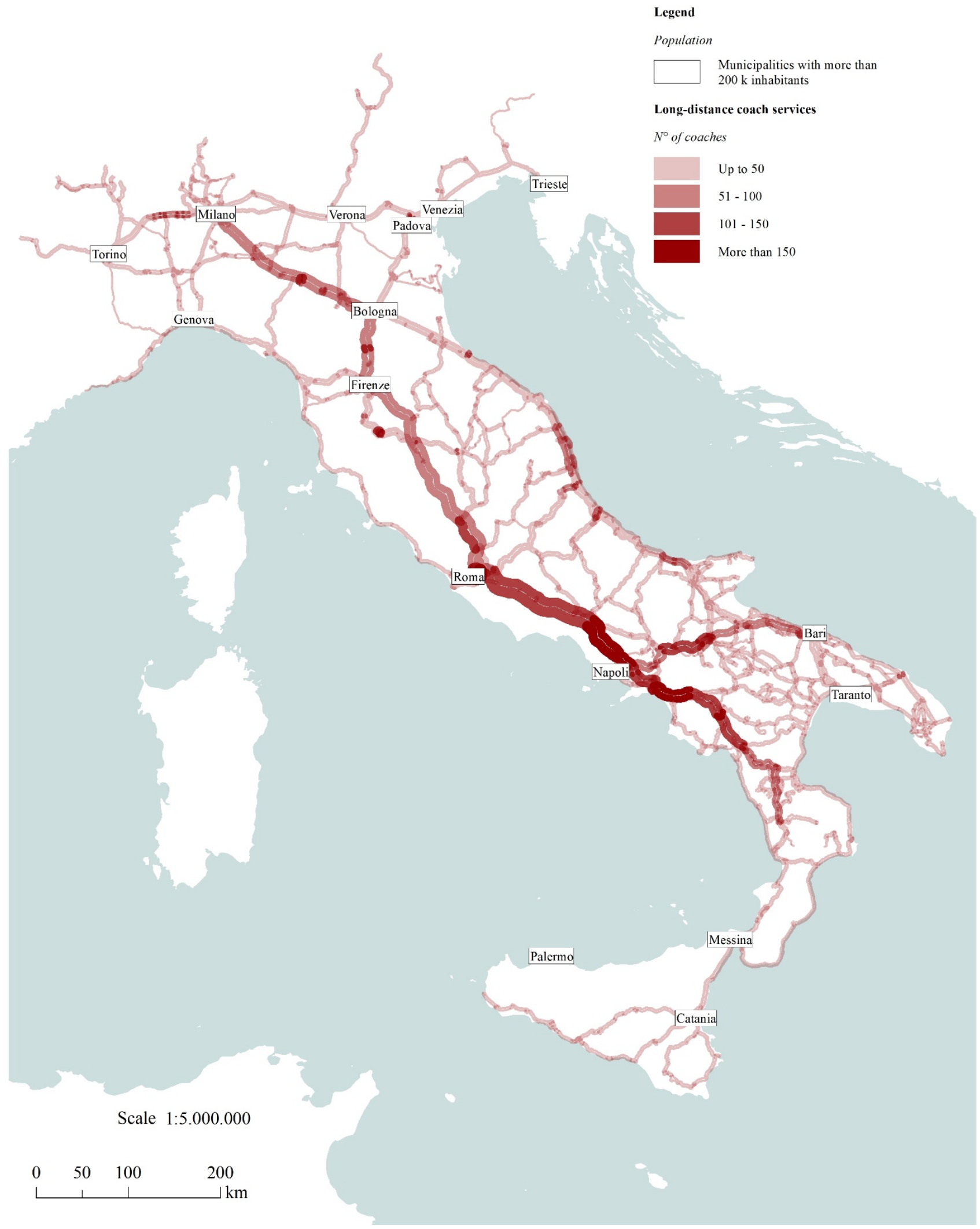

Figure 3. Long-distance coaches: number of daily services, year 2015/16. Source: our elaborations 
Italian urban structure explains at least part of this inhomogeneous supply (Beria et al., 2017c). The distribution of urban centres in the northern plain is completely different from the peninsular area. In the first case, a network of relatively near mid-sized cities hosts a large amount of population and a large amount of demand. In the latter, fewer and proportionately larger cities are separated by relatively empty areas (e.g. between Florence and Rome or between Naples and Bari). The urban structure in the north, however, is particularly unsuitable with a "traditional" high-speed model, given the limited distances between main centres and the absence of a single main attractor, like Rome or Naples for the south. This makes long-distance supply more scattered and, in some cases (for example the cities of Bergamo, Varese or Mantua) absent and based on effective regional connections with main centres.

\subsection{Passengers figures}

Italian transport statistics are scarcely revealing about detailed supply and demand figures. With the exclusion of ports and airports, only aggregated figures are available and often ignore that the market is no more in the hands of public companies. In particular, rail passengers' statistics are available in Trenitalia balance sheets divided between regional, long-distance PSO and market PSO. Coach figures are always estimations, as there is no centralised collection of data on supply and especially on demand. Air transport data is available at the OD level and passengers in ports are available per port. Highways release annually traffic counts per main segments.

Consequently, it is difficult to provide a complete and reliable estimation of long-distance traffic figures. Only recently, two documents (ART, 2017 and MIT, 2018) quantify long-distance passengers and passengers*km.

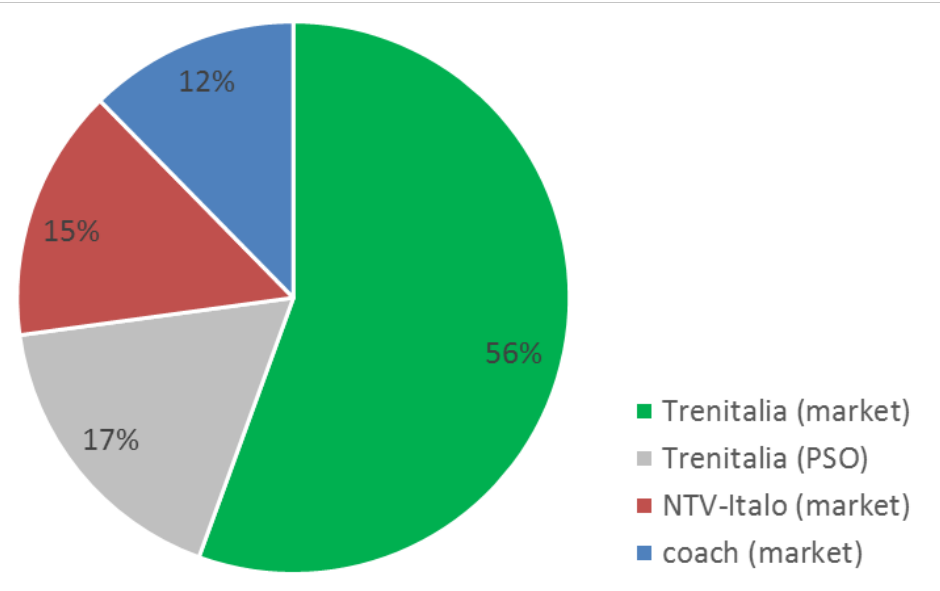

Figure 4. Estimation of long-distance passengers in Italy. Source: ART, 2017.

Limiting to land transport, the rail incumbent Trenitalia in 2016 served 59 Mpax, representing the 73\% of total passengers (Figure 4). The market component is largely dominant, representing $76 \%$ of Trenitalia's total. The newcomer NTV served 12 Mpax, representing a significant share of 15\%. An estimation of coach passengers tells about 10 Mpax, which is $12 \%$ of overall long-distance domestic market. Overall, $83 \%$ of Italian domestic long-distance passengers use market services, i.e. not planned by a public authority and not subsidized. 


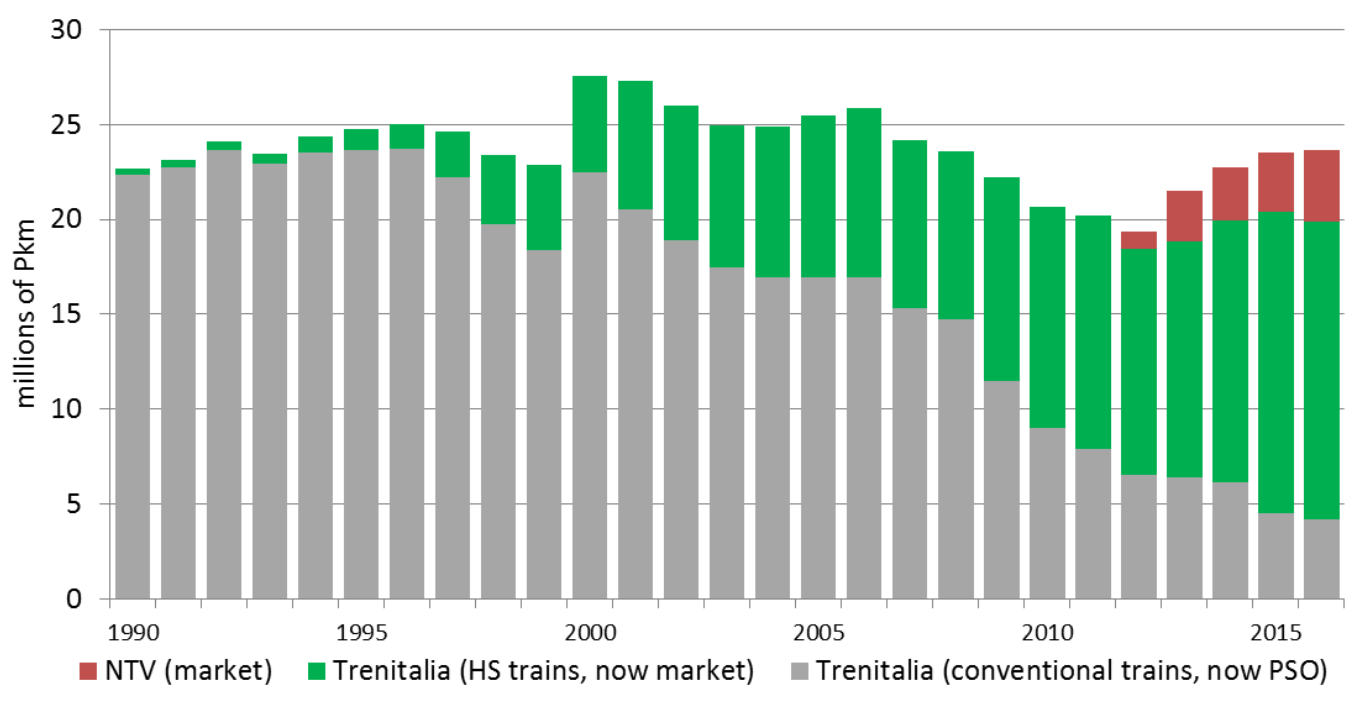

Figure 5. Trend of long-distance rail passengers*km in Italy. Source: MIT, 2018 integrated with company data for 2016.

Limiting to rail passengers, it is interesting to study the trend over the last 25 years. Figure 5 represents the passengers*km according to companies balance sheets. Trenitalia's traffic is classified in two segments, whose meaning changed over years (explaining the rapid switch from one to the other). Initially, all trains were "conventional", excluding a few rides classified as "high-speed" because using new high-speed rolling stock. During the 2000s' there was a progressive reclassification of trains, aimed at dividing the market segment from trains under PSO, which is now complete. The chart shows this progressive substitution, with all market trains now operated using multiple-unit trains and running on conventional and HS tracks according to the case, and PSO trains all operated using conventional trains. The chart also shows the entry of NTV trains since 2012, gaining a market share in terms of Pkm of $16 \%$.

It is interesting to notice that the Pkm travelled at national scale declined steadily since the 2000s' (excluding 2005-6), and rose again since 2013. The fall is due to the substitution of rail with air low-cost for the very long distances (e.g. Milan - Catania is more than 1,300 km and nowadays almost no more trains are operated), which reduced both passengers and $\mathrm{km}$. After competition on the HS started in 2012, the series is increasing again, because passengers are increasing, but the average distance is lower than in the past (e.g. Milan - Rome is about $600 \mathrm{~km}$ ). More interesting is the fact that NTV did not reduce Trenitalia's traffic but rather contributed to increase the overall market to levels that now are similar to the years before the low-cost "boom".

\section{Measuring competition}

\subsection{Market services and PSO in "competition”}

The rail incumbent Trenitalia has defined, since 2009, a relatively simple train classification, based on three main types: the brand "LeFrecce" includes the entire long-distance market segment ${ }^{6}$ (Figure 2); Intercity is the name of long-distance PSOs (about 100 trains per day, including both day and night services); Regional (which includes also the disappearing fast interregional trains) subsidised by the Regions.

The nature of the three is clearly different. The market segment receives no subsidies. Ministry of Transport theoretically plans the Intercity, but there is no trace of a pro-active attitude of the planner, to neither expand, change or reduce the perimeter of the PSO. Simply, Trenitalia declares some trains as unprofitable and the

\footnotetext{
${ }^{6}$ The brand LeFrecce is further divided in three sub-levels Frecciarossa (full high-speed), Frecciargento (mixed HSconventional) and Frecciabianca (conventional), which will be commented later.
} 
Ministry has always paid their existence. ${ }^{7}$ Regional trains are planned and subsidised by the Regions, sometimes in couples if the service is cross-border. In general, however, interregional trains have been radically reduced (or split) over years, as they were used also for medium of long-distance routes, which Trenitalia prefers to concentrate on its market segment.

Despite the differences and the tentative to separate clearly the three segments, Italian geography is such that there is no actual boundary between regional and long-distance, especially in some areas (e.g. Adriatic coast) where there is almost no solution of continuity in the urban areas for 7-800 km. Therefore, overlaps between services are unavoidable and this creates a sort of "internal competition" between long-distance market services, PSOs and Regionals. ${ }^{8}$

To analyse these overlaps, we compute the $\mathrm{HHI}^{9}$ of Trenitalia, for every OD connecting the 107 Italian provincial capitals, separating the three segments "LeFrecce", Intercity and Regional. Of course they are not "in competition", but their prices and level of service are sufficiently varied and their planner is different (Trenitalia, Ministry and Regions) that they can be considered as different products.

$$
\mathrm{HHI}_{\mathrm{TI}}=\text { share }_{\mathrm{LeFrecce}}{ }^{2}+\text { share }_{\mathrm{IC}}{ }^{2}+\text { share }_{\text {Regional }}^{2}
$$

Results (Figure 6) are quite revealing: $47.9 \%$ of all OD couples served directly (853 out of 1,779) have more than one train type and consequently present overlaps between subsidised and market trains. In many cases the HHI is relatively low (very few have 0.9 or more) and this means that the overlap between services is substantial. Interestingly, even if we exclude the Regional trains, the share of ODs with both market and PSOs trains remains very similar, $47.4 \%$. Weighting each OD with the train frequency, the overlapping routes are among the most served, as 7,162 trains out of 9,545 (75.0\%) operate between origins and destinations with $\mathrm{HHI}<1$.

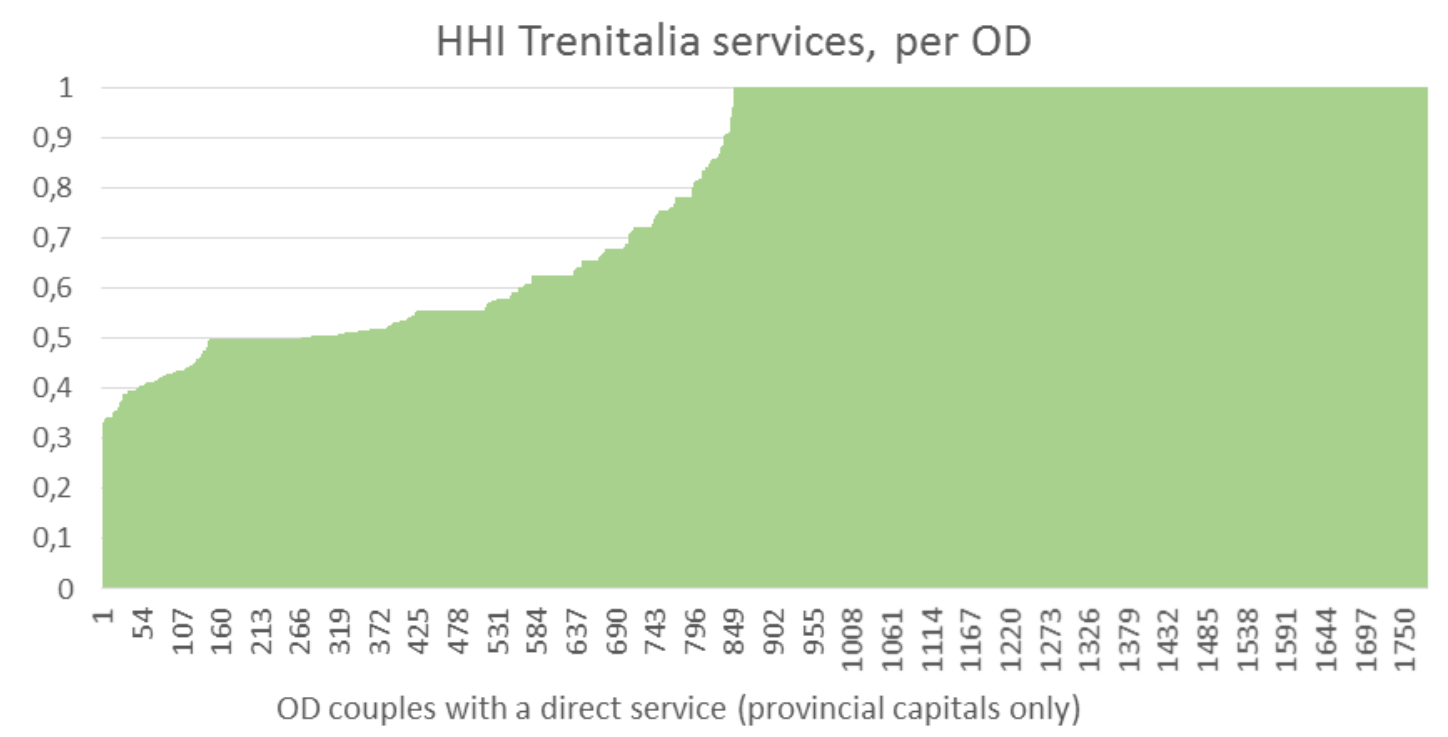

Figure 6. HHI of Trenitalia services (LeFrecce, IC, Regional), per OD, year 2016. Our elaborations on official timetables.

To understand if this picture has changed, we perform the same elaboration for 2008 . With respect to 2008 the number of direct connections between provincial capitals reduced from 2,291/day (of which 1,682 excluding Regional trains) to 1,779/day (1,504 without Regional). Overlaps (routes with $\mathrm{HHI}<1$ ) were more in 2008

\footnotetext{
${ }^{7}$ In 2017 the concession of these trains have been extended for 10 years, and the subsidy has been raised - as requested by the incumbent - from 200 to 350 Millions of Euro per year.

${ }^{8}$ Many examples are possible. Between Milan and Genoa there are direct fast regional trains (approx. every 2h), Intercity (every 1h) and some LeFrecce and Thello (both market services). In the southern regions of Apulia and Calabria, Intercity and Regional trains often form together a regular timetable (e.g. every $1 \mathrm{~h}$ ).

${ }^{9}$ The Herfindal-Hirshman Index is the sum of the squares of market shares. HHI=1 means perfect monopoly, HHI=0 means perfect competition. $\mathrm{HHI}=0,5$ means that 2 competitors are perfectly comparable.
} 
(52.6\%), but less if we exclude regional trains (34.6\%). These apparently counterintuitive findings depend from the fact that in 2008 the Intercity segment was much larger, including also non-PSO routes.

\subsection{The extent of NTV competition in 2016}

The entry of NTV in 2012 has changed radically the Italian rail market (Beria \& Grimaldi, 2017; Beria et al., 2018a). After a ramp-up period, characterised by a progressive put into operation of all trains and tuning of services, the supply consolidated in the last years. ${ }^{10}$

Referring to 2016, 4.5\% (80) of direct connections between provincial capitals have $\mathrm{HHI}<1$ because operated also by NTV. Despite few, these routes are among the most important ones and, in fact, their weight in terms of trains circulating is as much as $14.1 \%$ of all trains circulating in Italy. The national average HHI, weighted with train frequency, is 0.96 .

$$
\begin{gathered}
\mathrm{HHI}=\text { share }_{\text {Trenitalia }}{ }^{2}+\text { share }_{\mathrm{NTV}}{ }^{2} \\
\mathrm{HHI}_{\mathrm{LD}}=\text { share }_{\text {Trenitalia Long-distance }}{ }^{2}+\text { share }_{\mathrm{NTV}}{ }^{2}
\end{gathered}
$$

Also excluding regional trains, the picture does not change substantially: the 80 ODs represent the $5.3 \%$ of all ODs operated directly and $24 \%$ of trains serve routes with both operators. The weighted national average $\mathrm{HHI}_{\mathrm{LD}}$ of the long-distance segment alone falls to 0.91 . This is probably among the highest level of rail competition in Europe, but the "game reserve" of the incumbent Trenitalia remains very large.

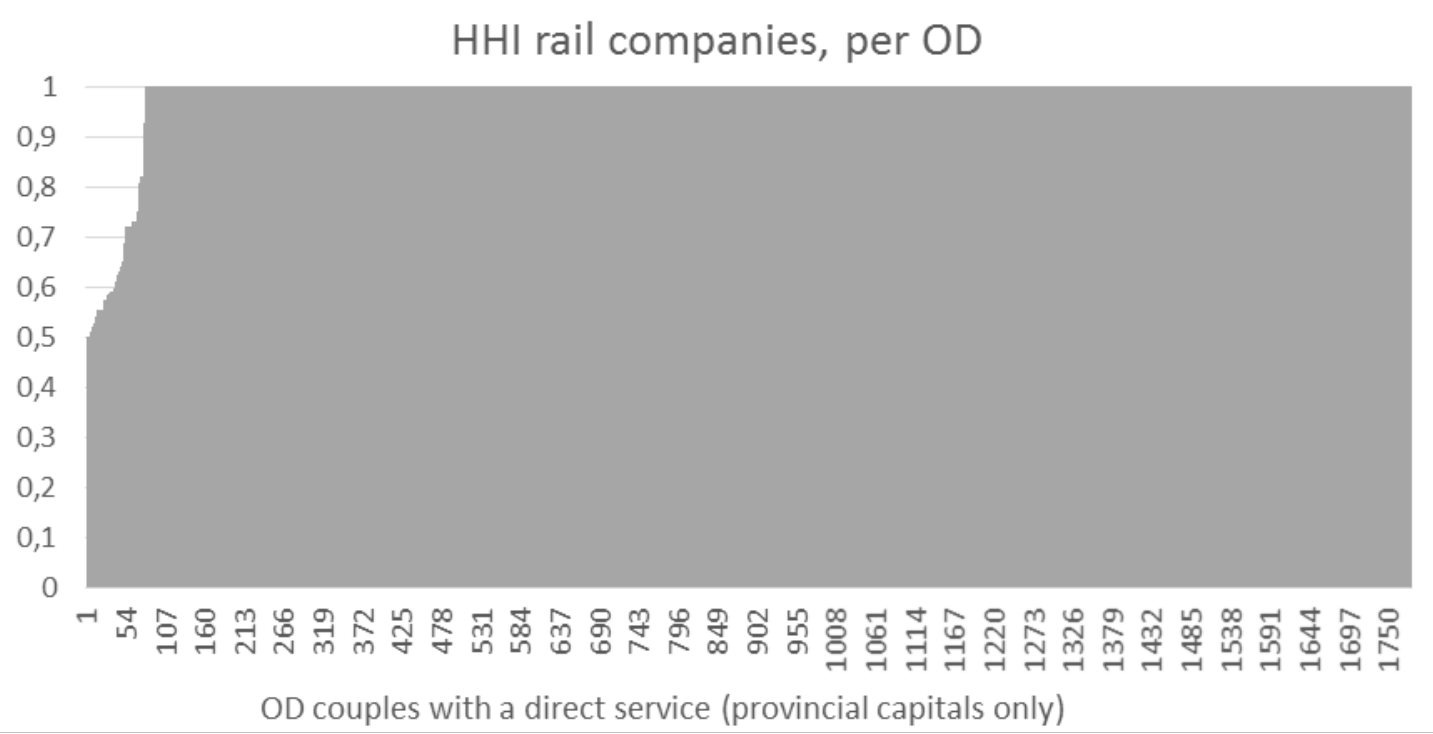

Figure 7. Intramodal HHI of rail services, per OD, year 2016. Our elaborations on official timetables.

The degree of competition is however different across routes. Figure 7 reports HHIs ordered from the most competitive OD to the least. There is a dozen of ODs with HHI 0.5, i.e. with the two operators almost perfectly equal in terms of train frequency. The other 80 ODs in competition show increasing HHI, with the highest the least competitive route - between Padua and Venice $(\mathrm{HHI}=0.93)$, where the huge number of regional trains blurs the market share of NTV.

\subsection{Intermodal competition}

In addition, coach industry is contributing to competition. A direct rail connection does often not exist among all OD pairs, especially when cities are small and/or far. In many cases, coach has been a solution for that, guaranteeing a direct connection among places otherwise unconnected. More recently, coach has become a

\footnotetext{
${ }^{10}$ The recent buy of further trains will change again the picture in 2018, especially with the entry in the Milan - Venice route.
} 
direct competitor to train also on served routes and we have a number of OD pairs where both rail and coach exist and share the same customer base.

Considering the 2,630 OD pairs served directly by both means of transport, $32 \%$ are served by coach only, $39 \%$ by train only but the remaining $29 \%$ is in competition. Similarly to previous figures, we can compute the modal HHI per OD to understand the extent of such competition (Figure 8). Since the capacity of coaches is smaller than for trains, we defined two indicators, one related to frequency only (1 train vs. 1 coach) and the other one weighting with seats ( 1 train $=300$ seats, 1 coach $=50$ seats).

$$
\begin{gathered}
\mathrm{HHI}_{\text {bus|rail_freq }}=\text { share }_{\text {bus_frequency }}{ }^{2}+\text { share }_{\text {rail frequency }}{ }^{2} \\
\text { HHI }_{\text {bus|rail_seats }}=50 \cdot \text { share }_{\text {bus_frequency }}{ }^{2}+300 \cdot \text { share }_{\text {rail frequency }}{ }^{2}
\end{gathered}
$$

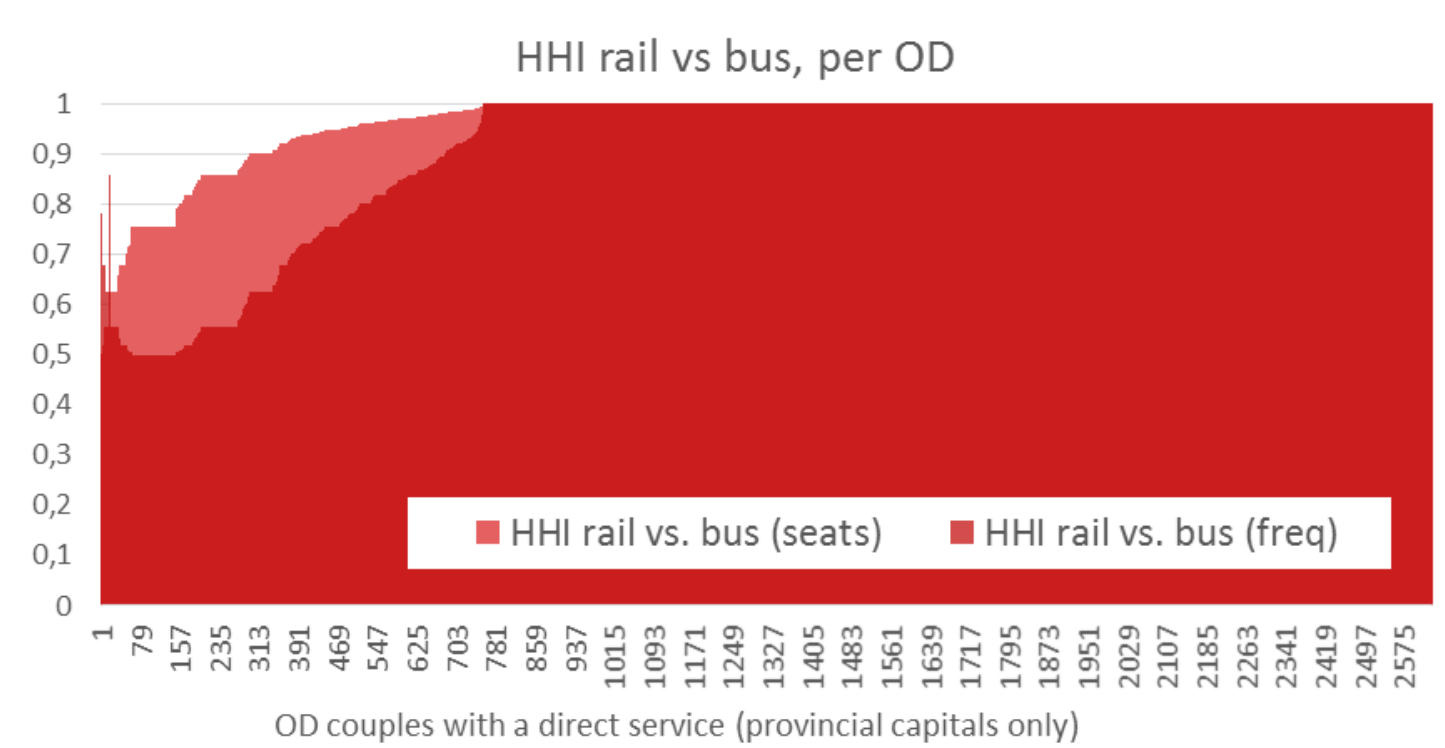

Figure 8. Intermodal HHI including rail and coach services, per OD, year 2016. Our elaborations on official timetables.

In the $29 \%$ of routes with both modes, $8 \%$ of ODs are served more frequently by coaches rather than by trains. In general, HHI computed on frequency is more equilibrate, with a significant share of routes (about $10 \%$ ) with HHI not far from 0.5 and only a few where the secondary mode is marginal. Of course, weighting with seats, the dominance of train is stronger. However, the presence of both modes may influence positively prices and quality, especially for passengers with lower willingness-to-pay.

\subsection{Comments}

The analysis have shown that a significant part of the long-distance market (in terms of ODs and, especially, of passengers) is operated under competition. Just one third of OD pairs between main cities is served by rail incumbent only, under monopoly conditions. Another third is served by coaches only, but these routes are the thinnest of the country and coach sector is rather competitive, with numerous bus companies. The remaining third is served by both coach and rail. The two modes are just partially substitute (we will come back on this later), but increasing frequency of coach services is making it more and more a relevant option at least for lowincome users.

Rail segment itself is not monolithic: not only a newcomer operates many of the main OD pairs also, but also there is a sort of "internal competition" between PSOs and market trains. This overlap is however potentially problematic, distorting the market and possibly preventing competitor from serving some routes. In the following, we will discuss the level of prices observed in the markets and the possible effect of competition on them. 


\section{$5 \quad$ Fares in a (partially) liberalised market}

The disappearing of regulated fares in the long-distance, thanks to the relatively pervasive liberalisation occurred in some European countries, allows most of long-distance companies to set price strategies to optimise revenues and maximise margins.

Fares are extremely different according to mode, company, period, class and level of competition. The practice of yield management is used pervasively by most of main air and rail companies (Sauter-Servaes \& Nash, 2007; Malighetti et al., 2009; Hazledine, 2011; Alderighi, 2010; Alderighi et al., 2012; Salanti et al., 2012; Bergantino et al., 2015; Bergantino \& Capozza, 2015; Bilotkach et al., 2015; Beria et al., 2016; Capozza, 2016). Yield management consists in adapting the price to purchase conditions in order to rise the revenues for the company. At the same time, each mode is specialising more and more in sub-markets and fares vary accordingly. For example, train passed from being the "basic" transport mode for a country, to being the mode for the most demanding travel purposes in terms of frequency and speed. At the same time, the "democratisation" of air transport went on since the last two decades with the rise of low-cost carriers and the consequent fall in average and entry prices. More recently, the modes for low willingness-to-pay users are becoming coach and carpooling.

Price strategies adopted by each company depend on the willingness-to-pay of the customers (in turn depending on their purchasing power), but also on the level of intermodal and intramodal competition which determine their alternative options. For example, in the very long-distance, airplanes have no modal alternatives, but, at the same time, air market is extremely competitive on thicker routes. Instead, short-haul intercity connections, in absence of a developed coach sector, could make rich a rail monopolist.

In the following of the section, we aim at testing three hypotheses on fare behaviour, by means of a large dataset of fares collected in the Italian market of rail, coach and carpooling during different periods of 20162018.

H1: competitors have different price behaviour in terms of average fare;

H2: competitors have different price behaviour in terms of time trend;

H3: coach and rail markets partially overlap also in terms of fares.

For rail, we will use two price-per-km indicators: the cheapest daily fare and the daily average of cheapest fare. Referring to the example of Table 1, the first measure takes the lowest available price, whatever is the time of the day, which is 9 Euro at 12:00. The second measure computes the average of the lower prices for each service, in the example average $(30 ; 15 ; 9 ; 50)=26$ Euro. We have such observations for one year and 30 OD pairs, of which seven served also by the newcomer Italo.

\begin{tabular}{lcccc}
\hline Day 1 & $1^{\text {st }}$ class full fare & $2^{\text {nd }}$ class full fare & $2^{\text {nd }}$ class discounted fare & min \\
\hline Train 1 (7:00 - 9:00) & 50 & 30 & discount unavailable & 30 \\
\hline Train 2 (9:00-11:00) & 50 & 30 & 15 & 15 \\
\hline Train 3 (12:00 - 14:00) & 50 & 30 & 9 & 9 \\
\hline Train 4 (18:00 - 20:00) & 50 & unavailable (full) & discount unavailable & 50 \\
\hline
\end{tabular}

Table 1. Example of fares

For the coach, as we do not have the disaggregated observations, but just the monthly average and we will refer directly to it. For more details about calculation and database consistency, please refer to Annex.

\subsection{Intra-modal competition, average fares}

We initially compare the average price per km, per route, during 2017. Figure 9 shows the unit price per route in function of distance, both for Italo and Trenitalia's services, classifying the routes of the latter between those under competition and not. 


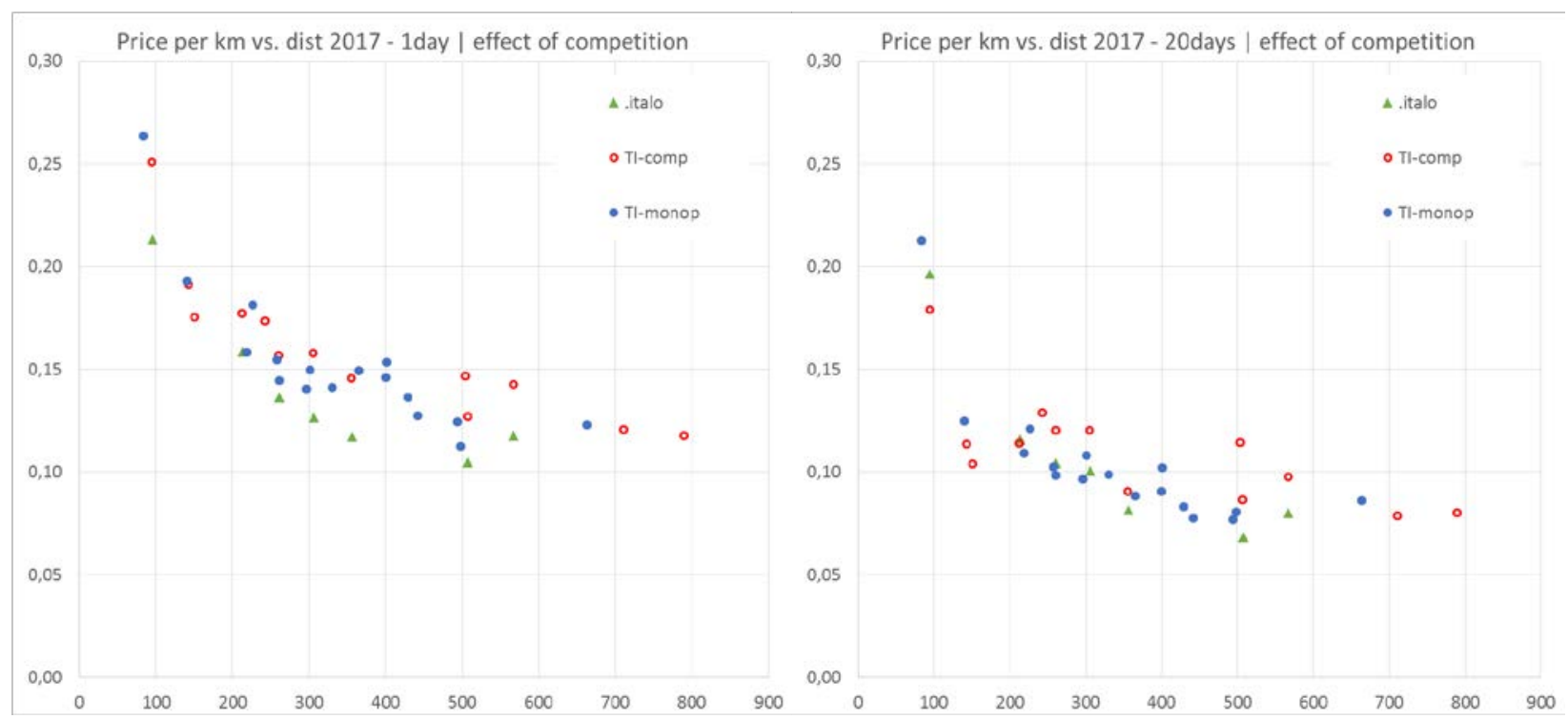

Figure 9. Effect of competition. Comparison of $€ / \mathrm{km}$ between Italo, Trenitalia in competition and Trenitalia in monopoly routes. 20 and 1-days advanced purchase, Monday-Friday.

Prices are substantially affected by the distance, ranging from about $25 € c e n t / k m$ on the shortest routes (Milan - Brescia and Florence - Bologna) one day in advance, to about $12 €$ cent/km on 7-800 km routes. Purchasing tickets in advance (20 days, in the example) allows saving about $5 €$ cent $/ \mathrm{km}$.

Looking at Italo's prices, we see that it is, as expected, systematically cheaper than the incumbent (see Table 2), except for the two shortest routes 20 days before departure. It slimmer organisation allows to lower production costs (Giuricin, 2018) and to stay on a lower price level, compatible with its minor market share and lower network effect.

Interestingly, Trenitalia's prices are not significantly different between ODs in competition and in monopoly (rather the opposite). In other words, Trenitalia is not pricing, as one would expect, more on routes where is alone with respect to routes where Italo is present. This apparently counterintuitive fact should be considered in the light of evolution of competition over years. Trenitalia prices were 20-30\% higher before 2012, as already documented in literature (Cascetta \& Coppola 2015; Desmaris, 2016), but this decrease is now stabilised and no price-war is taking place. Moreover:

a. the routes analysed and in particular those where NTV is present, are among the "richest" in the country and where high-speed fostered the shift of business and tourism traffic ${ }^{11}$ to rail, which is usually associated to higher prices;

b. too high prices could push NTV to expand fleet and network, which actually happened between Milan and Venice;

c. Trenitalia learned that yield management can be used everywhere maximising revenues despite lowering past prices. ${ }^{12}$

\footnotetext{
11 The above point at $500 \mathrm{~km}$ is the Rome-Venice OD, a typical route of international tourism.

12 This is not uncommon. French SNCF has introduced the low-cost Ouigo services, both to maximize its revenues from the lower willing-to-pay customers and to prevent the entry of competitors (Crozet, 2016; Crozet \& Guihery, 2018).
} 


\begin{tabular}{clccc}
\hline OD distance & \multicolumn{1}{c}{ OD } & 1 day before & 10 days before & 20 days before \\
\hline 95 & Bologna - Florence & $-15 \%$ & $0 \%$ & $10 \%$ \\
213 & Milan - Bologna & $-10 \%$ & $-3 \%$ & $2 \%$ \\
261 & Rome - Florence & $-13 \%$ & $-11 \%$ & $-13 \%$ \\
306 & Milan - Florence & $-20 \%$ & $-14 \%$ & $-16 \%$ \\
356 & Rome - Bologna & $-19 \%$ & $-13 \%$ & $-10 \%$ \\
507 & Rome - Verona & $-18 \%$ & $-18 \%$ & $-21 \%$ \\
567 & Milan - Rome & $-17 \%$ & $-22 \%$ & $-18 \%$ \\
\hline
\end{tabular}

Table 2. Comparison of NTV vs. Trenitalia prices, on selected routes. Average of 2017 cheapest tickets, 10-days advanced purchase.

In conclusion, we can affirm (H1) that competitors price differently, but routes under competition, in the particular case of Italy, are not necessarily cheaper than the monopoly ones, as already found in literature for air transport (Malighetti et al., 2014). Price-war is just one of the possible outcomes of competition (Tomes et al., 2014), and is not the case of Italy. The two companies behaved quite effectively (NTV after 2017) to maximise prices avoiding predatory practices, which were not necessary in a context of rising demand, shifted from air and private car.

\subsection{Intra-modal competition, time trends}

Differences between the two competitors can be seen also in the temporal dimension. Referring to more than 2 years of fares, we plotted the monthly average of the lowest fares available on all trains serving a route. Figure 10 shows three significant routes, two in competition and one served only by the incumbent, mostly by PSO trains and a few of commercial ones. 


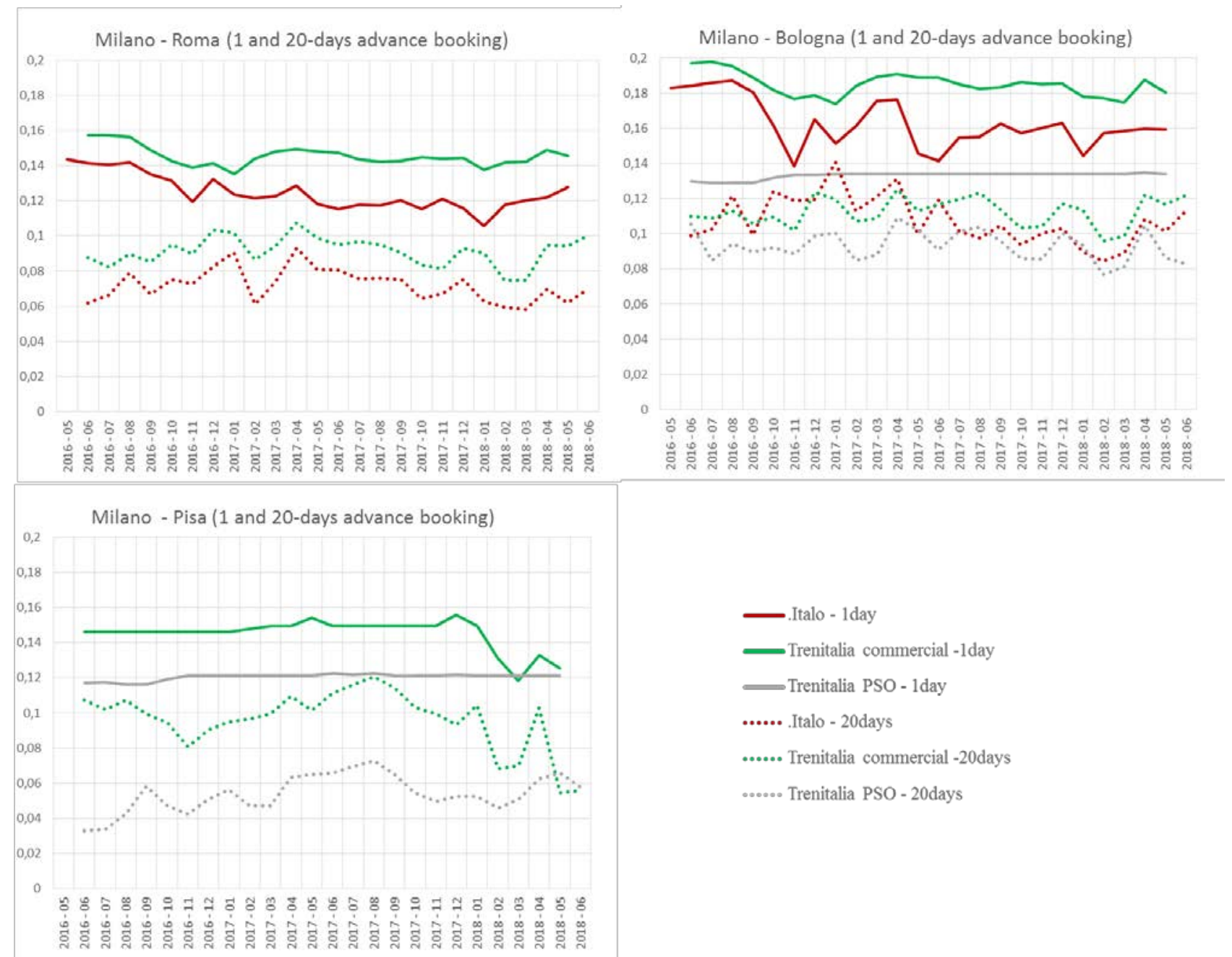

Figure 10. Analysis of time trend of average lower fares, comparison between Italo and Trenitalia's commercial and PSO trains. 1 and 20 days of advanced purchase.

The first case is that of the Milan - Rome, an important route with scarce seasonal variability. The presence of Italo is consolidated in the analysed period. The 20-days advance series shows very well how similar, especially since 2017, is the behaviour of the two competitors, with Italo prices rather constantly $20 \%$ cheaper. 1-day before departure Trenitalia prices are very steady, showing that they reached the expected load factors all year long. Before 2017 Italo had prices nearly 20\% higher than now and Trenitalia partially, too. We do not know the impact of such price decrease on revenues, but Italo changed price strategy and - at the same time raised load factors, probably obtaining a better turnover.

The 2017 repositioning is even more visible on the Milan - Bologna route. It is much shorter and has also a significant component of commuting traffic (it is just 1h ride). Italo's price decrease occurred in 2017 is perfectly visible, in both periods, occasionally reaching the level of the subsidised Intercity. Initially, Italo even proposed tickets more expensive than the competitor, 20 days in advance. Now, similarly to Milan Rome, Trenitalia prices tend to be very constant, while Italo is not. Interestingly, 20-days in advance Trenitalia's commercial and PSO services are perfectly parallel.

The fact that yield management is used also in PSO routes can be appreciated in the Milan - Pisa route. Here just a few trains run in the market segment and the majority is a PSO. The route is also more seasonal than the other two and summer prices are well above winter ones. Trenitalia's market services enjoy a large fare premium, much larger than on Milan - Bologna, as the IC are rather slow but very frequent. An interesting fact is that (except the very last months) 1-day before departure all prices are constant, which means that discounted fares are no more available. The absence of competition allows Trenitalia to price the basic fare even if the train is not full. 
In general, all observed routes show variability due to the period of the year (H2), but also that companies' strategies have changed, such as Italo’s repricing occurred since 2017.

\subsection{Intermodal competition}

Evidences of partial overlapping of coach and rail markets, including high-speed one, are already found in literature (Beria et al., 2018b). Figure 11 collects all unitary prices per km obtained for every OD couple, for rail and coach. To have a clearer picture of land transport, we added also carpooling prices, obtained from Blablacar platform. ${ }^{13}$ Differently from previous charts, all related to the lowest available rail fare, here we include also non-discounted $2^{\text {nd }}$ and $1^{\text {st }}$ class prices, in order to have a better picture of price positioning of the different modes.

\footnotetext{
${ }^{13}$ For a similar overview of airfares in function of distance, one can refer to Malighetti et al. (2014). For example, they obtain asymptotic functions of prices per $\mathrm{km}$ of Ryanair and easyJet ranging from $0.20-0.25 € / \mathrm{km}$ for shortest 2-300 km routes, to $0.05 € / \mathrm{km}$ or less for longer routes. Ryanair is systematically below easyJet. The most interesting finding, however, is that routes in competition are not cheaper than routes without competition, as found also by ourselves in Figure 8.
} 


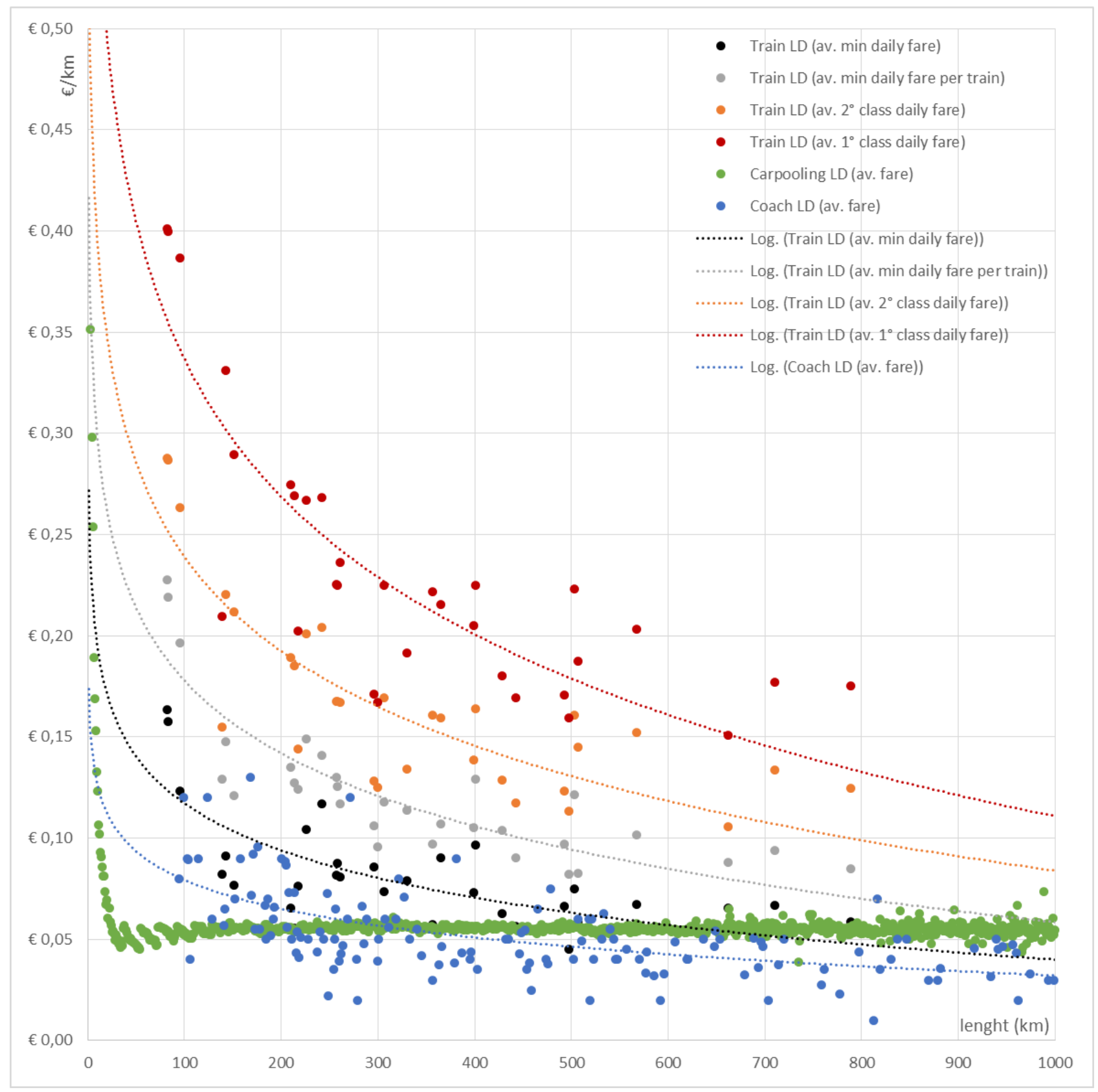

Figure 11. Distribution of fares (€/km) for all Italian long-distance services. Source: our elaborations.

In general, notwithstanding the natural variability of observations, we can recognise relatively clear price policies (H3), approximated for readability's sake with a set of logarithmic functions describing a progressive reduction of $€ / \mathrm{km}$ as distance increases. The figure contains:

1. The daily average of $1^{\text {st }}$ class flexible fare (all available trains);

2. The daily average of $2^{\text {nd }}$ class flexible fare (all available trains);

3. The daily average of the lowest discounted fare (all available trains);

4. The lowest daily fare available (the cheapest train);

5. The monthly average of coach fares;

6. The average of Blablacar "fares".

Interestingly, rail fares are always above the two competing modes (with full fares even 4 or 5 times higher, according to distance travelled). However, looking at the lowest train fare, the trend becomes very similar to the average coach fare, ranging from $+50 \%$ to $+25 \%$ at $1,000 \mathrm{~km}$ or more. What is more, looking at single prices, there are numerous situations in which the cheapest train option is well below a similarly long coach 
route. In other words, if one traveller is adaptable and have no train preference, he can find rail tickets that are sometimes not significantly higher than a coach option or even cheaper. Actually, it appears that coach companies assume the lowest train fare as the highest price that a possible user is willing to pay for their service.

Different are the considerations for carpooling. This "mean” of transport, by definition (Chan et al., 2012), is not intended to result in a financial gain. Consequently, the contribution depends linearly on distance through gasoline price plus, possibly, highway toll. This particular situation allow carpooling to be the cheapest option, both in respect to coach and train, only up to $200 \mathrm{~km}$. In the range between 200 and $400 \mathrm{~km}$ coach becomes competitive and on higher distances carpooling prices more than the cheapest train tickets. In this sense, the claim that carpooling is threatening and competing on price with long-distance public transport is true limitedly to the shortest routes, while public transport returns cheaper for the longest.

\subsection{Comments}

Pricing has evolved profoundly since the liberalisation and the end of monopolistic production in the hands of a national railway company. Now all operators (both rail companies and the majority of coach ones) use yield management techniques, variously sophisticated. Except carpooling, public modes have unit prices decreasing with distance.

Italo has prices 0 to $20 \%$ lower than the incumbent Trenitalia, according to the route and the advanced purchase. Coach average prices are lower than the cheapest train option from about $50 \%$ on short routes to about $25 \%$ on longer routes. However, single routes can be cheaper in the case of rail. In general, we may affirm that the upper bound of fares variability is dominion of the train, but in the lower bound rail, coach and carpooling partially compete, according to the route characteristics.

\section{Specialisation (product differentiation vs. focus)}

As we have shown, Italian market is characterised by a quite complex competitive environment, where both monopolistic and fully opened markets exist. This has consequences in terms of fares differentiation (as shown in the previous chapter), but also more generally in a specialisation of services. Industrial organisation literature classically defines three strategies of companies to gain (or maintain) a competitive advantage (Porter, 1985): cost leadership, product differentiation and product focus. The issue has already been discussed for rail openaccess in Europe (Beria \& Grimaldi, 2017), showing that most of competitors specialise, by focusing on niche markets, or becoming cost leader thanks to a no-frills strategy. The incumbent, instead, to maintain its leadership without changing too much its cost structure, has the possibility to differentiate its products, in terms of speed, price, classes, comfort, etc. Figure 12 depicts this fact, showing the main Italian operators and their general strategy. In the following of the section, we will discuss the horizontal axis of the scheme, i.e. the specialisation process, from a traditional network monopolist model to a differentiated business model or to a niche-market model. 


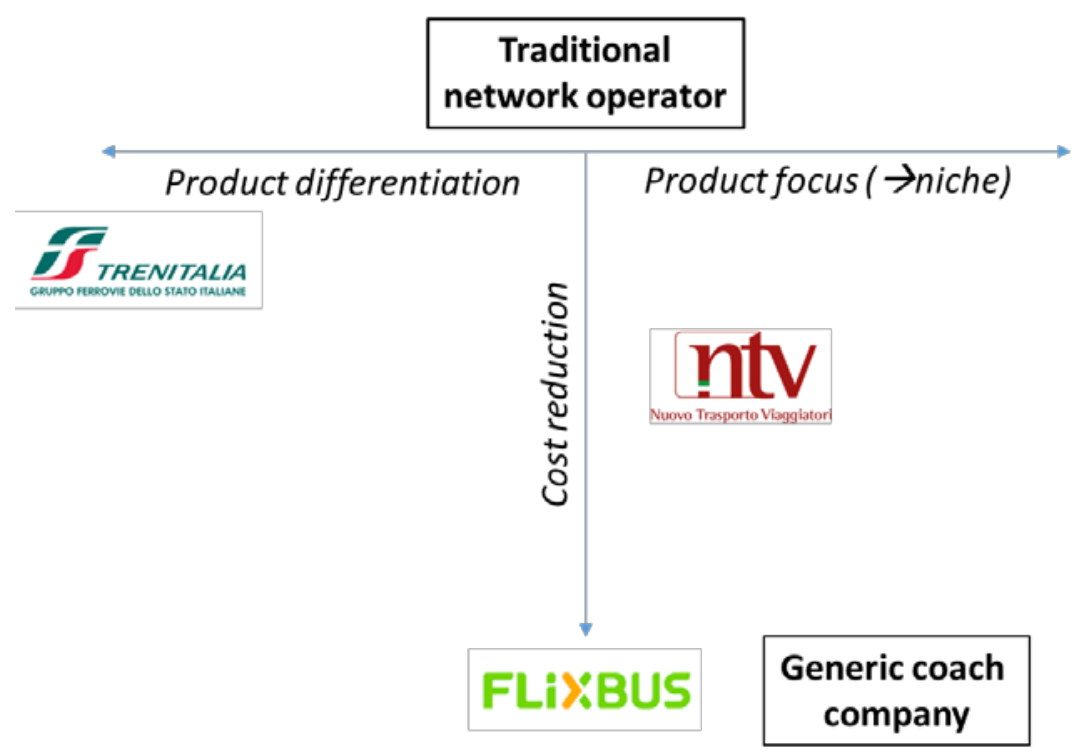

Figure 12. Strategies of long-distance companies. Source: our elaborations.

To give evidence to such specialisation process, we will compute (Figure 13 and Figure 14) four measures for all relevant service types in Italy in 2016: commercial speed, capillarity, route length and average price per $\mathrm{km}$.

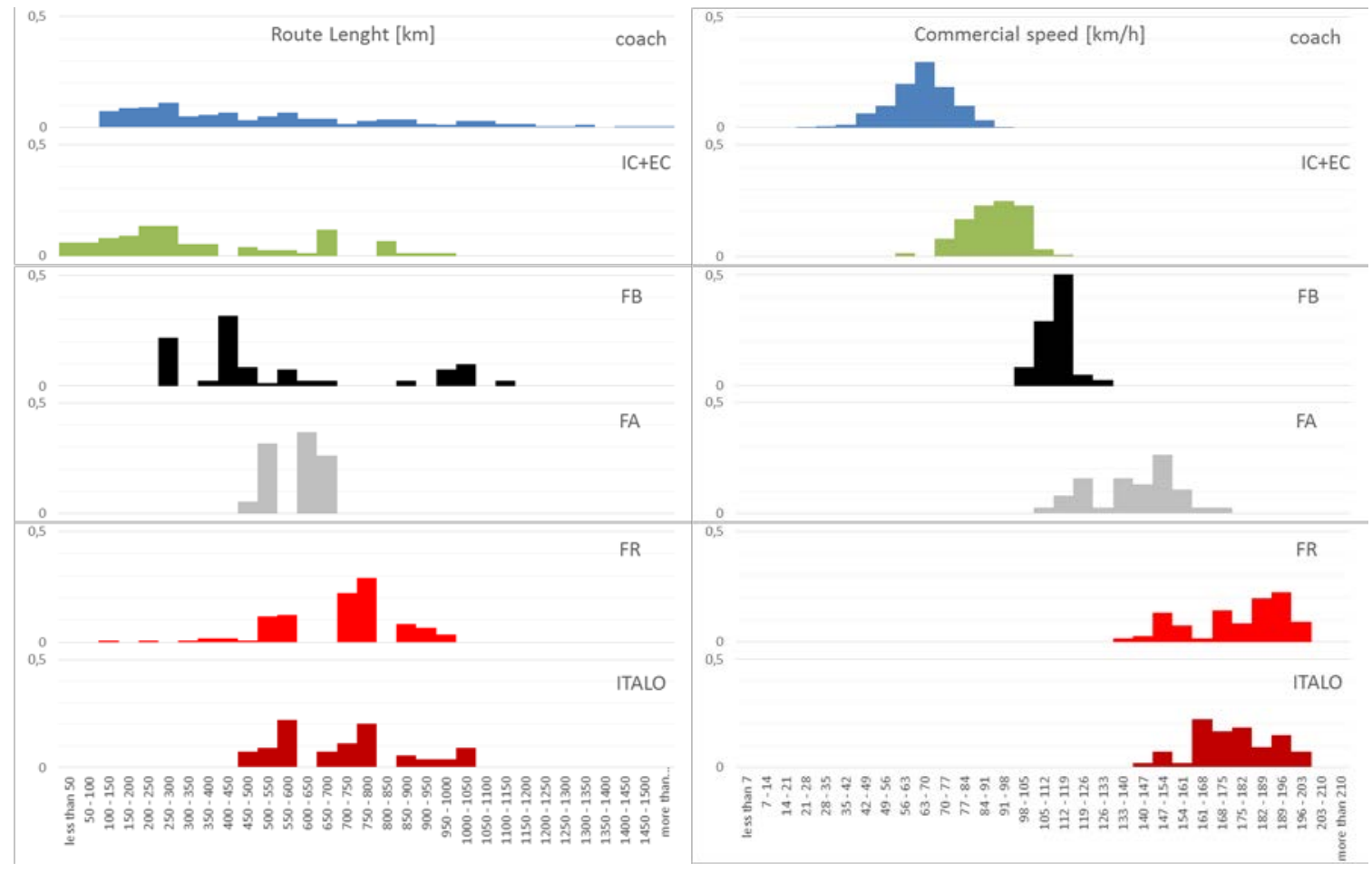

Figure 13. Product differentiation: distribution of route length (left) and commercial speed (right) 


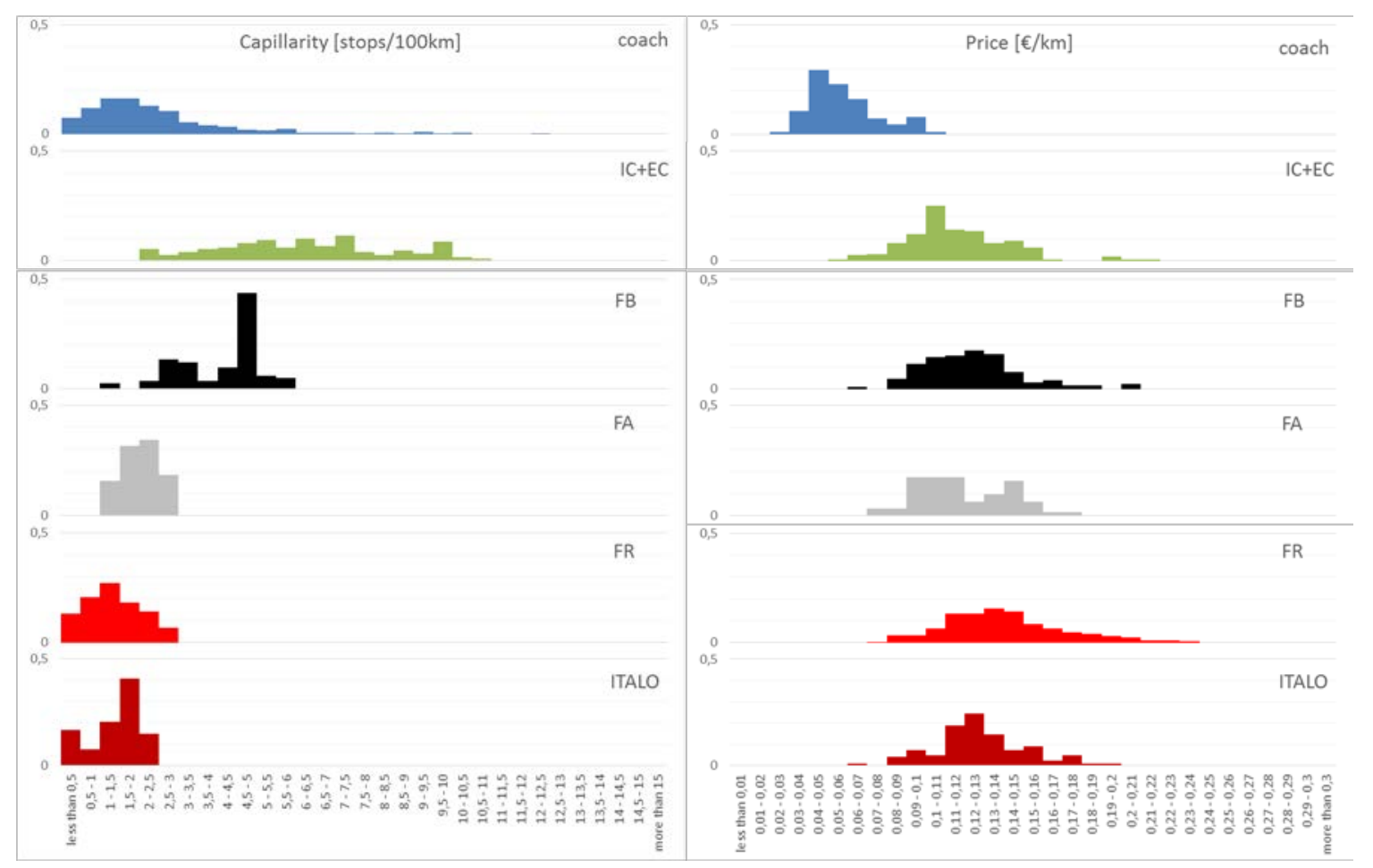

Figure 14. Product differentiation: distribution of stops frequency (left) and price per km (right)

\subsection{Product differentiation in rail market}

Niche-products are, in a rail market that has its strength in the network effect, limited. International cases show that niche operators, when can survive, remain absolutely marginal and unlikely to modify incumbent's behaviour. The general tendency is, rather, to differentiate products. The French SNCF is probably the incumbent differentiating more, even offering two levels of high-speed trains: the classical TGV and the lowcost Ouigo, the latter using old and high-capacity rolling stock, calling at secondary stations but offering very low fares (Crozet, 2016; Crozet \& Guihery, 2018).

The two Italian operators pursue different strategies, also because of their different dimension and market size. NTV is focusing on HS segment only (which is, in a certain sense, a "niche" - despite very large), while Trenitalia offers a broader range of services: Frecciarossa are the high-speed trains, Frecciargento the mixed high-speed and conventional services and Frecciabianca the other commercial services fully on conventional tracks. The remaining long-distance trains, classified as Intercity or IntercityNotte (night trains) are all under PSO (Figure 2). We can clearly isolate these products in terms of speed, capillarity, price and comfort ${ }^{14}$.

Trains branded as Frecciarossa use the faster rolling stock are actually running at the highest commercial speed and on distances normally between 400 and 1,000 km (Turin - Naples) and calling at few stations. ${ }^{15}$ The competitor Italo is placed exactly on the same market, with average commercial speed a bit higher. Interestingly, Trenitalia has recently introduced a handful of slow and long services. For example, Frecciarossa trains from Milan to Bari using the fast tracks only for $200 \mathrm{~km}$. Clearly, the financial sustainability of such services is questionable and often they are introduced due to political pressures.

Frecciabianca services have lower speed, between 100 and $120 \mathrm{~km} / \mathrm{h}$, and distance ranges between 250 and $1,150 \mathrm{~km}$. Frecciargento's speed is in between thanks to the parts using fast tracks. They all range between 400 and $700 \mathrm{~km}$ because they all end in Rome. At the bottom range of the chart, the slow PSO Intercity trains,

\footnotetext{
${ }^{14}$ For example, recent trainsets are configured in 3 or 4 classes instead of the classical 2.

15 The few shorter trains are early morning and evening rides, for example Milan - Turin or Rome - Naples, used by commuters.
} 
some of which are so slow and short that can hardly be defined as "long-distance" (e.g. Turin-Genoa) and should rather be interregional, if this category had not disappeared from Italian railways.

Prices differentiation is, in this context, extremely revealing. Theoretically, one would expect that at different products, correspond different prices: IC and Frecciabianca slower and cheaper, Frecciargento and Frecciarossa faster, newer and more expensive. This, interestingly, does not happen. IC prices are regulated and price level guarantees margins to the operator even with low load factors. HS trains does not cost more, thanks of the competitive pressure of Italo whose network is almost exactly corresponding to Trenitalia's top services.

\subsection{Coach transport: niches and global brands}

Coach market is, to a certain extent, more homogeneous, as the speed performance is strictly dependent from the vehicle and the Highway Code (ranging between 28 and $97 \mathrm{~km} / \mathrm{h}$ ). Vehicles, too, tend to be similarly configured and business models such as "luxury-coaches" existing in some countries never took place in Italy. The only significant product difference is between day- and night-coaches, the latter being common in the long North-South routes. Lines length spans from a few hundreds to $1,400 \mathrm{~km}$, but stops capillarity is, except few cases, rather limited (between one every $200 \mathrm{~km}$ to one every $30 \mathrm{~km}$ ) and well below IC trains which are their direct competitors.

Average prices are significantly lower than any train service, usually never reaching $10 € c e n t / \mathrm{km}$. The distribution of Figure 14 shows that a small group of routes has prices higher than the rest of the distribution. They are night services and the few cases of inconvenient rail connections in the short-haul.

Apparently homogeneous, the extreme fragmentation of the coach sector in about 100 companies, both historical and recently founded, guarantees a range of strategies in destinations and network structure. The larger operator, the newcomer Flixbus, is pursuing a typical strategy of global operator, offering a similar and connected network across the whole Europe. Smaller legacy carriers, instead, remain sometimes tied to their original business model, centred on the low-frequency model connecting sparse villages to main cities.

\section{An open issue for the future: market vs. PSO}

After having quantitatively discussed Italian situation, in this section, we will go back to a European scale, where a general deregulation path is well set, but some "collateral" regulatory issues actually exist and play an important role, in particular the "clash" between PSOs partially overlapping with market services.

Long-distance markets are normally deregulated in terms of fares, access to networks, entry and exit, etc. This is the case of all EU air transport and international coach and rail services. In addition, also domestic coach sector is liberalised in 14 EU countries (Steer Davies Gleave, 2016) and rail one, at least partially, in a dozen of countries. However, in a deregulated market, the overlap (even partial) with a regulated one might be disruptive for the profitability of both sides. This happens sometimes internally to a mode, but more often across modes or between different sub-markets. Being far from homogeneous, a number of important issues therefore exist:

- Some regulated sub-markets still exist, and often co-exist with liberalised segments. Typically, some air PSOs exist to connect minor European destinations (Calzada \& Fageda, 2014; Wittman et al., 2016; Hromádka, 2017; Fageda et al., 2018), but also in rail transport (for example in Italy, France or Switzerland);

- At the border between long-distance and regional transport, services of comparable characteristics may co-exist under completely different regulatory rules. This is the case of interregional trains serving similar destinations at similar travel times, but with different fares. In Sweden subsidized (and tendered) interregional services and night trains overlap on some relations with commercial intercity services (Fröidh \& Nelldal, 2015). The disappearing of many night trains, scarcely profitable due to air competition, has been the first outcome. At the same time the mortality of commercial new entrants 
have been high, due to a relative strength of the incumbent and its PSOs. In Italy the story has been slightly different, with the disappear of many interregional PSOs, in favor of commercial intercity and high-speed connections (Venditti, 2017). This, of course, has deprived some secondary towns of a decent service, but has also probably reduced the overall need for subsidies;

- Similarly, different modes can be differently regulated. Night trains (subsidised) compete with coaches and air transport (deregulated and not contributed). Liberalised coaches may also serve the same markets of interregional trains or buses. This lack of border is problematic for both businesses: regulated regional services could be cherry-picked by targeted commercial services; commercial services could suffer of unfair competition from subsidised services, especially when provided by incumbents;

- In addition, hidden subsidies often exist within fully deregulated markets. Route development policies, sometimes in form of direct subsidies, sometimes as co-marketing practices, are often used by airports to attract low-cost carriers (Laurino \& Beria, 2014; Halpern \& Graham, 2015; Núñez-Sánchez, 2015; Ramos-Pérez, 2016; Gössling et al., 2017). These subsidies have the effect of artificially lower air fares on some routes. National railways usually maintain (for political or network reasons) losing market services, cross subsidising them with other services, whose price is relatively increased. Moreover, coach companies owned by railway undertakings are claimed to be covertly subsidised by the mother-companies (Guihéry \& Gremm, 2018);

This overlap has two main consequences. The first one is that one (or both) between PSO and commercial service is doomed to suffer or adapt. A seamless co-existence is unlikely, as probably one would disappear, or adapt, or move to niche, or specialise (e.g. business-travels), or just lose money. Secondly, the overlapping is increasingly problematic in more integrated networks. This is why air transport, where point-to-point traffic prevails and fare integration does not exist or can be managed within the company, is the most liberalised. To the contrary, in rail, where network effect and integration are pillars of the system, a mixed regime (regulated and deregulated) is potentially disruptive for all (van de Velde, 2014) and thus exists just where a large demand gives room both to point-to-point and network suppliers.

\section{Conclusion}

Long-distance passenger segment has radically changed in Europe during the last two decades, and even more in the last years. Many public investments have been done and both European and national regulations have changed, but the main fact is that most of long-distance transport moved from being a (sometimes loosely) planned monopolistic segment, to a (sometimes strongly) competitive market-driven initiative.

Backed by the most recent literature, we presented in the paper a quantitative overview of the main elements related to such evolution of long-distance passenger transport, by means of a case-country, Italy. We focused on three main aspects: market concentration, fares and specialisation patterns.

In the first, we showed that both rail and coach offer a significant number of OD pairs in Italy, but also that on the core of the rail market the competition between the incumbent Trenitalia and the newcomer NTV/Italo is actual, being the latter a non-marginal competitor. We have also documented that Trenitalia has differentiated its long-distance services and that on many routes either high-speed, conventional and regional trains co-exist. Concentration has reduced with respect to the past decade, when Trenitalia was the only operator and coach sector was less developed, but at the same time the "internal competition" between PSO and market services of the incumbent decreased.

Prices are one of the most relevant element potentially changed by a deregulation process. Italy shows that prices are significantly lowered by competition (but also quality is increased), to a level where the incumbent is no more capable to extract a rent from top-services, such as high-speed ones. In fact, we have found no significant gap between different market products, including subsidised ones, whatever is the presence or not of the direct competitor. At the same time, prices become very volatile according to the period of the year, load 
factor, and even single train. In addition, classes become more differentiated, ranging from low-cost advancedpurchase tickets to flexible business seats. Overall, the lower price level is that of coaches and the higher of rail services (both PSO and market HS), effectively capped by a fierce competition on the top-services. Carpooling lays in between, resulting the cheapest only for shorter routes.

Finally, we have shown to what extent long-distance companies adapted their products, moving from a general "homogeneous supply network model" to a significant specialisation in terms of mode, speed, comfort, capillarity and prices. This tendency is likely to go on, even if its main dynamics have deployed in a relatively short time of less than 10 years.

In conclusion, one question remains open and left to future works: is market initiative actually sustainable in the long-run (van de Velde, 2014)? With respect to the past, a deregulated and competitive environment is more dynamic and mergers \& failures are a natural and likely event. However, competition is expected to be something that does not harm the sector overall. For example, low-cost airlines that survived the mortality of the first years, are apparently there to stay, as well as legacy carriers remained. Moreover, the coach sector, in mature markets, has consolidated but competition has not disappeared. However, theory has given advices about the potential instability of such markets. For example, Button (2002) has theorised the existence of an "empty core" in the airline market, which brings a natural instability to the sector. Preston (1999), Ivaldi \& Vibes (2005) and Johnson \& Nash (2012) studied the conditions for head-on competition in rail, advising that there is a very limited space for stable solutions (basically, a significant cost advantage in a niche market). In contrast with these theoretical expectations, Swedish, Austrian and especially Italian competitors faced difficulties, but look as potentially capable to survive and expand.

\section{References}

Aarhaug, J., \& Fearnley, N. (2016). Deregulation of the Norwegian long distance express coach market. Transport Policy, 46, 1-6.

Alderighi, M. (2010). Fare dispersions in airline markets: A quantitative assessment of theoretical explanations. Journal of Air Transport Management, 16(3), 144-150.

Alderighi M., Nicolini M., \& Piga C. (2012). Combined Effects of Load Factors and Booking Time on Fares: Insights from the Yield Management of a Low-Cost Airline, Quaderni di Dipartimento, No. 171

Alexandersson, G., \& Hultén, S. (2008). The Swedish railway deregulation path. Review of Network Economics, 7(1).

Alexandersson, G., Hultén, S., Fearnley, N., Longva, F. (2010). Impact of regulation on the performances of long-distance transport services: a comparison of the different approaches in Sweden and Norway. Research in Transportation Economics, 29(1), 212-218.

Augustin, K., Gerike, R., Sanchez, M. J. M., \& Ayala, C. (2014). Analysis of intercity bus markets on long distances in an established and a young market: The example of the US and Germany. Research in Transportation Economics, 48, 245-254.

ART (2017). Rapporto annuale 2017. Autorità di Regolazione dei Trasporti. Torino, Italy.

Bergantino, A. S., \& Capozza, C. (2015). One price for all? Price discrimination and market captivity: Evidence from the Italian city-pair markets. Transportation Research Part A: Policy and Practice, 75, 231244.

Bergantino, A. S., Capozza, C., \& Capurso, M., 2015. The impact of open access on intra-and inter-modal rail competition. A national level analysis in Italy. Transport Policy 39, 77-86.

Beria, P., Niemeier, H. M., \& Fröhlich, K. (2011). Alitalia-the failure of a national carrier. Journal of Air Transport Management, 17(4), 215-220.

Beria, P., Niemeier, H. M., \& Fröhlich, K. (2013). How Liberalization Can Go Wrong: the Case of Alitalia. In: Forsyth et al. (2013). Liberalization in Aviation: Competition, Cooperation and Public Policy. Ashgate. 
Beria, P., Redondi, R., \& Malighetti, P. (2016). The effect of open access competition on average rail prices. The case of Milan-Ancona. Journal of Rail Transport Planning \& Management, 6(3), 271-283.

Beria, P., \& Grimaldi, R. (2017). Reality and opportunities for on-track competition in HSR. In: Albalate (2016, eds) Evaluating High-Speed Rail: Interdisciplinary Perspectives, 7, 140.

Beria P., \& Nistri D. (2017). Rapporto sul Mercato delle Autolinee a Lunga Percorrenza in Italia | Semester I 2017. TRASPOL Report 2/17 \& Checkmybus. Milano, Italy.

Beria P., Nistri D., \& Laurino A. (2017a). Rapporto sul Mercato delle Autolinee a Lunga Percorrenza in Italia | Anno 2016. TRASPOL Report 1/17 \& Checkmybus. Milano, Italy.

Beria P., Ferrara E., Debernardi A., \& Bertolin A. (2017b). QUAINT - QUantitative Analysis of Italian National Transport. Deliverable 1. Mid-term Report. Milano, Italy.

Beria, P., Debernardi, A., \& Ferrara, E. (2017c). Measuring the long-distance accessibility of Italian cities. Journal of Transport Geography, 62, 66-79.

Beria, P., Grimaldi, R., Albalate D., \& Bel G. (2018a). Delusions of success: Costs and demand of high-speed rail in Italy and Spain. Transport Policy, 68, 63-79.

Beria, P., Nistri, D., \& Laurino, A. (2018b). Intercity coach liberalisation in Italy: Fares determinants in an evolving market. Research in Transportation Economics.

Bilotkach, V., Gaggero, A. A., \& Piga, C. A. (2015). Airline pricing under different market conditions: Evidence from European Low-Cost Carriers. Tourism Management, 47, 152-163.

Blayac, T., \& Bougette, P. (2017). Should I go by bus? The liberalization of the long-distance bus industry in France. Transport Policy, 56, 50-62.

Button K. (2002). Empty Cores in Airlines Markets. 5th Hamburg Aviation Conference. Hamburg.

Calzada, J., \& Fageda, X. (2014). Competition and public service obligations in European aviation markets. Transportation Research Part A: Policy and Practice, 70, 104-116.

Capozza, C. (2016). The effect of rail travel time on airline fares: First evidence from the Italian passenger market. Economics of Transportation, 6, 18-24.

Cascetta, E., \& Coppola, P. (2015). New High-Speed Rail Lines and Market Competition: Short-Term Effects on Services and Demand in Italy. Transportation Research Record: Journal of the Transportation Research Board, (2475), 8-15.

Chan, N. D., \& Shaheen, S. A. (2012). Ridesharing in north america: Past, present, and future. Transport Reviews, 32(1), 93-112.

Crozet Y. (2016). Le low-cost représente-t-il l'avenir du rail? Le Rail, Groupe Actis: 32-33. https://halshs.archives-ouvertes.fr/halshs-01394653/document

Crozet, Y., \& Guihéry, L. (2018). Deregulation of long distance coach services in France. Research in Transportation Economics.

Desmaris, C. (2016). High speed rail competition in Italy: A major railway reform with a" win-win game"? International Transport Forum Discussion Paper.

Dürr, N. S., \& Hüschelrath, K. (2017). Patterns of entry and exit in the deregulated German interurban bus industry. Transport Policy, 59, 196-208.

Dürr, N. S., Heim, S., \& Hüschelrath, K. (2016). Deregulation, competition, and consolidation: The case of the German interurban bus industry. Journal of Transport Economics and Policy (JTEP), 50(2), 164-188.

EC (1992). The Future Development of the Common Transport Policy: A Global Approach to the Construction of a Community Framework for Sustainable Mobility. Commission of the European Communities.

EC (2009). Green Paper. Ten-T: A policy review. Towards a better integrated transeuropean transport network at the service of the common transport policy. Commission of the European Communities. 
EC (2011). White Paper. Roadmap to a Single European Transport Area - Towards a competitive and resource efficient transport system. Commission of the European Communities.

ECA (2018). Special report n 19/2018: A European high-speed rail network: not a reality but an ineffective patchwork. European Court of Auditors

Fageda, X., Suárez-Alemán, A., Serebrisky, T., \& Fioravanti, R. (2018). Air connectivity in remote regions: A comprehensive review of existing transport policies worldwide. Journal of Air Transport Management, 66, 65-75.

Fröidh, O., \& Nelldal, B. L. (2015). The impact of market opening on the supply of interregional train services. Journal of Transport Geography, 46, 189-200.

Giuricin A. (2018). Ownership change heralds expansion at Italo-NTV. Railway Gazette International, May 2018.

Gössling, S., Fichert, F., \& Forsyth, P. (2017). Subsidies in aviation. Sustainability, 9(8), 1295.

Grimaldi R., Augustin K., \& Beria P. (2017). Intercity coach liberalisation. The cases of Germany and Italy. Transportation Research Procedia 25C (2017) 474-490.

Guihéry L., \& Gremm C., (2018, forthcoming). New intercity bus services in Germany and France: Can they make money? Research in Transportation Economics, XX-XX.Halpern, N., \& Graham, A. (2015). Airport route development: A survey of current practice. Tourism Management, 46, 213-221.

Hazledine, T. (2011). Legacy carriers fight back: Pricing and product differentiation in modern airline marketing. Journal of Air Transport Management, 17(2), 130-135.

Hromádka, M. (2017). Definition of public service obligation potential in the new EU member states. Transport Problems: an International Scientific Journal, 12(1).

Ivaldi, M., \& Vibes, C. (2005). Intermodal and intramodal competition in passenger rail transport, IDEI Working Paper no. 345, Toulouse: IDEI.

Johnson, D., \& Nash, C. (2012). Competition and the provision of rail passenger services: A simulation exercise, Journal of Rail Transport Planning \& Management, 2(1), 14-22.

Laurino, A., \& Beria, P. (2014). Low-cost carriers and secondary airports: Three experiences from Italy. Journal of Destination Marketing \& Management, 3(3), 180-191.

Malighetti, P., Paleari, S., \& Redondi, R. (2009). Pricing strategies of low-cost airlines: The Ryanair case study. Journal of Air Transport Management, 15(4), 195-203.

Malighetti, P., Redondi, R., \& Salanti, A. (2014). Competitive vs. monopolistic routes: Are fares so different?. Research in Transportation Economics, 45, 3-8.

MIT (2018). Allegato al DEF 2018. Connettere l'Italia: lo stato di attuazione dei programmi per le infrastrutture di trasporto e la logistica. Ministry of Infrastructure and Transport. Rome, Italy.

Núñez-Sánchez, R. (2015). Regional public support to airlines and airports: An unsolved puzzle. Transportation Research Part E: Logistics and Transportation Review, 76, 93-107.

Ponti, M., Boitani, A., \& Ramella, F. (2013). The European transport policy: Its main issues. Case Studies on Transport Policy, 1(1), 53-62.

Porter, M. E., \& Advantage, C. (1985). Creating and sustaining superior performance. Competitive advantage, 167.

Preston, J., Wardman, M., \& Whelan, G. (1999). An analysis of the potential for on-track competition in the British passenger rail industry. Journal of Transport Economics and Policy, 33(1), 77-94.

Ramos-Pérez, D. (2016). State aid to airlines in Spain: An assessment of regional and local government support from 1996 to 2014. Transport Policy, 49, 137-147. 
Salanti, A., Malighetti, P., \& Redondi, R. (2012). Low-cost pricing strategies in leisure markets. Tourism management, 33(2), 249-256.

Sauter-Servaes, T., \& Nash, A. (2007). Applying low-cost airline pricing strategies to European railroads. Transportation Research Record: Journal of the Transportation Research Board, (1995), 1-8.

Steer Davies Gleave (2016). Comprehensive Study on Passenger Transport by Coach in Europe. (No. MOVE/D3/2014-261). DG MOVE, Bruxelles.

Tomeš, Z., Kvizda, M., Nigrin, T., \& Seidenglanz, D. (2014). Competition in the railway passenger market in the Czech Republic. Research in Transportation Economics, 48, 270-276.

van de Velde, D. (2014). Market initiative regimes in public transport in Europe: Recent developments. Research in transportation economics, 48, 33-40.

Venditti G. (2017). Inter-Regio rail services, an opportunity for a structured transport system. Paper presented at "Long-distance passengers transport: market, planning, innovation”, Milan, 28-29 September 2017.

White, P., \& Robbins, D. (2012). Long-term development of express coach services in Britain. Research in Transportation Economics, 36(1), 30-38.

Wittman, M. D., Allroggen, F., \& Malina, R. (2016). Public service obligations for air transport in the United States and Europe: Connectivity effects and value for money. Transportation Research Part A: Policy and Practice, 94, 112-128.

\section{Annex: unit fares calculation}

In respect to long-distance trains, real fares were collected directly from the websites of Trenitalia and Italo since May 2016. With this method, we are able to know for each train the single fare variation during time but we do not have any information on the exact moment in which a potential user will actually buy that option. In order to overcome this missing information, we decide to take into consideration only fares referred to services departing after 10 days from the booking operation. Overall, we observed all trains connecting 60 origin-destination couples in Italy for 130 days, obtaining about 7,800 daily observations.

Furthermore, this typology of service attract, more than coach and carpooling, users with a wide range of willingness to pay. In order to describe also this variable, we collect information on fares related with different service classes (low-cost, $2^{\circ}$ class and $1^{\circ}$ class).

On the base of previous assumptions, two average $€ / \mathrm{km}$ per route are calculated as follow:

$$
\text { Average min. daily fare (Train } L D)=\frac{\frac{1}{n} \sum_{i=1}^{n} a_{i}}{k m}
$$

where:

$a$ is the minimum tariff, observed on that single route, between all the trains operating on day $i$; $n$ is the total number of days surveyed.

$\mathrm{km}$ is the single route length (from train station A to train station B).

$$
\text { Average min. daily fare per service }(\operatorname{Train} L D)=\frac{\frac{1}{n} \sum_{i=1}^{n}\left(\frac{1}{m} \sum_{l=1}^{m} b_{l}\right)_{i}}{k m}
$$

where:

$b$ is the minimum tariff, observed on that single route, for train $l$ operating on day $i$;

$m$ is the total number of trains surveyed on day $i$ on that single route;

$n$ is the total number of days surveyed.

$\mathrm{km}$ is the single route length (from train station A to train station B). 
To calculate the average $2^{\circ}$ and $1^{\circ}$ class daily fare we substitute, in the previous formula, the value of variable $b$ with the single fare respectively related with $2^{\circ}$ and $1^{\circ}$ class service.

Data on long-distance coaches were provided from the online platform Checkmybus since January 2016 (Beria et al., 2017a; Beria \& Nistri, 2017). The initial database includes the average monthly price on 188 routes in Italy, for all companies operating. The entire database includes 18 months between 2016 and 2017. From this data, we averaged the companies' information, obtaining the average $€ / \mathrm{km}$ payed by users travel on a certain distance.

This value was calculated as follow:

$$
\text { Average fare }(\operatorname{Coach} L D)=\frac{\frac{1}{n} \sum_{i=1}^{n}\left(\frac{\sum_{l=1}^{m} c_{l} w_{l}}{\sum_{l=1}^{m} w_{l}}\right)}{k m}
$$

where:

$c$ is the average monthly tariff, observed on that single route, for service $l$ operating on month $i$;

$w$ is the total number of ticket sold for service $l$ on month $i$ on that single route;

$m$ is the total number of coach company surveyed on month $i$ on that single route;

$n$ is the total number of month surveyed.

$\mathrm{km}$ is the single route length (from the centroid of municipality A to the centroid of municipality B) ${ }^{16}$

Finally, in respect to long-distance carpooling, real contributions (assimilated to fares) were collected through an automatic procedure directly from the websites of BlaBlaCar, from March 2015 to November 2015. Data represent the real trips posted by each driver on the online platform between every OD relation where the starting point or an intermediate stop correspond with an Italian regional or provincial capital. In total, we observed 356,000 trips along 81 days. As contributions are not fixed, but every drivers has the possibility to variate (inside a certain range) the price that his passenger will pay for that lift, we refer to the route average. To calculate the average carpooling daily fare on distance we utilize the following formula:

$$
\text { Average fare (Carpooling } L D)=\frac{\left(\frac{\sum_{i=1}^{n} d_{i} w_{i}}{\sum_{i=1}^{n} w_{i}}\right)}{k m}
$$

where:

$d$ is the single contribution surveyed on day $i$ for each OD relation;

$w$ is the total number of time that the contribution $d$ was choose by a driver;

$n$ is the total number of day surveyed.

$\mathrm{km}$ is the single route length (from the centroid of municipality A to the centroid of municipality B) ${ }^{17}$

\footnotetext{
${ }^{16}$ Source: ISTAT (2014, November 30). Matrici di contiguità, distanza e pendolarismo. Retrieved October 30, 2017, from http://www.istat.it/it/archivio/157423

${ }^{17}$ See note 16
} 